PRISCILA CARVALHO MIRANDA

ANÁLISE DOS NÍVEIS DE COMPOSTOS SULFURADOS VOLÁTEIS E SUA RELAÇÃO COM RINOSSINUSITE CRÔNICA

BRASÍLIA

2016 


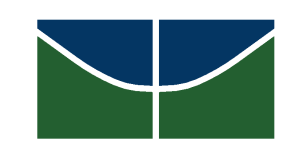

UNIVERSIDADE DE BRASÍLIA

FACULDADE DE MEDICINA

PROGRAMA DE PÓS-GRADUAÇÃO EM CIÊNCIAS MÉDICAS

PRISCILA CARVALHO MIRANDA

\section{ANÁLISE DOS NÍVEIS DE COMPOSTOS SULFURADOS VOLÁTEIS E SUA RELAÇÃO COM RINOSSINUSITE CRÔNICA}

Dissertação apresentada como requisito parcial para a obtenção do título de Mestre em Ciências Médicas pelo Programa de Pós-Graduação em Ciências Médicas da Universidade de Brasília

Orientador: Prof. Dr. Rivadávio Fernandes Batista de Amorim

Coorientadora: Profa. Dra. Denise Pinheiro Falcão da Rocha 
Ficha catalográfica elaborada automaticamente, com os dados fornecidos pelo(a) autor(a)

MM672a

Miranda, Priscila Carvalho

Análise dos níveis de compostos sulfurados

voláteis e sua relação com rinossinusite crônica / Priscila Carvalho Miranda; orientador Rivadávio Fernandes Batista de Amorim; co-orientador Denise Pinheiro Falcão da Rocha. -- Brasília, 2016. $81 \mathrm{p}$.

Dissertação (Mestrado - Mestrado em Ciências Médicas) -- Universidade de Brasília, 2016.

1. Halitose. 2. Sinusite. 3. Diagnóstico. 4. Compostos de enxofre. I. de Amorim, Rivadávio Fernandes Batista, orient. II. da Rocha, Denise Pinheiro Falcão, co-orient. III. Título. 


\section{PRISCILA CARVALHO MIRANDA}

Análise dos Níveis de Compostos Sulfurados Voláteis e sua Relação com Rinossinusite Crônica

Dissertação apresentada como requisito parcial para a obtenção do título de Mestre em Ciências Médicas pelo Programa de Pós-Graduação em Ciências Médicas da Universidade de Brasília

Orientador: Prof. Dr. Rivadávio Fernandes Batista de Amorim

Coorientadora: Profa. Dra. Denise Pinheiro Falcão da Rocha

Aprovado em: 04/08/2016

\section{BANCA EXAMINADORA}

Presidente: Prof. Dr. Rivadávio Fernandes Batista de Amorim

Instituição: Universidade de Brasília - UnB

Prof. Dr. Márcio Nakanishi

Instituição: Hospital Universitário de Brasília - HUB

Profa. Dra. Maria do Carmo Machado Guimarães

Instituição: Universidade de Brasília - UnB

Profa. Dra. Roberta Lemos Vieira Bezerra

Instituição: Hospital Universitário de Brasília - HUB 


\section{AGRADECIMENTOS}

A Deus, por abençoar minhas escolhas e me amparar nos momentos difíceis;

À Universidade de Brasília e ao Hospital Universitário de Brasília, minha segunda casa, por me permitirem a concretização de mais um sonho;

Aos meus pais, fonte de apoio incondicional, amor e os mais bonitos valores na vida;

Ao meu noivo Fellipe Cardoso, pelo carinho e compreensão nesta fase;

Ao professor Rivadávio Amorim pela oportunidade e orientação nesta jornada;

À professora Denise Falcão pela disponibilidade em ajudar sempre da melhor forma possível, pela coorientação e pelas lições de publicação científica, de estatística e, principalmente, de vida. A senhora é uma grande inspiração;

Ao Dr. Márcio Nakanishi, exemplo de dedicação e entusiasmo que nos motiva;

Ao Dr. Gustavo Bachega e Dr. Jader Reis, por permitirem a coleta no Hospital de Base do Distrito Federal e auxiliar no recrutamento dos pacientes;

À Comissão de Aperfeiçoamento de Pessoal do Nível Superior (CAPES) pela bolsa concedida para realização deste estudo;

Aos residentes e à equipe do Hospital Universitário de Brasília e do Hospital de Base do Distrito Federal pelo auxílio no recrutamento dos pacientes;

Ao Renato Augusto de Lima, pela disposição e auxílio na coleta dos dados;

Aos funcionários da Secretaria de Pós-Graduação da Faculdade de Medicina, especialmente ao Gledson Alessandro Ribeiro da Silva, pela disponibilidade e empenho em sempre nos auxiliar;

Às técnicas em enfermagem Paula Fernandes e Anagecira Santos e às secretárias Marineth Leite e Vanda Maia pela preciosa ajuda;

Ao Dr. Sérgio Arruda, que me iniciou no meio científico, me incentiva e até hoje vibra com minhas conquistas. Obrigada por todas as lições;

À amiga Monique Scalco por todo o estímulo e apoio, além de ajuda nas fotografias; 
Às técnicas Rita Lopes e Maria da Paz Costa, por gentilmente colaborarem na execução das fotografias;

Aos amigos e familiares que de alguma forma estiveram comigo nesta caminhada. 
"O conhecimento une cada um consigo mesmo e todos com todos."

José Saramago 


\section{RESUMO}

Introdução: A rinossinusite crônica (RSC) é uma doença inflamatória que acomete a mucosa nasossinusal e tem como sintomas cardinais a obstrução nasal, rinorreia, dor facial e hipo/anosmia. A halitose pode ser definida como uma alteração na qualidade do odor do ar exalado e causa ansiedade e constrangimento social. Os compostos sulfurados voláteis (CSV) são produtos da degradação de aminoácidos e uma das causas do mau odor bucal. Apesar de a RSC ser citada frequentemente como causa de halitose, pouco se sabe na literatura sobre a prevalência ou associação desta condição à RSC. Objetivo: comparar os níveis de CSV oral e nasal de pacientes com e sem RSC. Objetivos secundários: analisar o odor bucal dos pacientes com e sem RSC por meio do teste organoléptico e medida de CSV oral; avaliar se a prevalência de halitose nos pacientes com RSC é maior que a de pacientes sem RSC. Métodos: Neste estudo observacional transversal, foram selecionados 26 pacientes com diagnóstico médico de RSC atendidos consecutivamente em dois serviços terciários de Otorrinolaringologia (Hospital Universitário de Brasília e Hospital de Base do Distrito Federal) e 26 pacientes sem RSC provenientes dos mesmos serviços. Todos os pacientes foram avaliados por uma médica otorrinolaringologista e por um cirurgião dentista, quando era realizada coleta de dados demográficos e clínicos, exame físico otorrinolaringológico, halimetria (teste organoléptico, CSV oral e nasal), sialometria e avaliação periodontal. Os resultados foram analisados por meio do teste de Shapiro-Wilk, teste $\mathrm{t}$ de Student para amostras independentes e teste qui-quadrado considerando o valor de $p<0,05$ para significância estatística. Resultados: Não houve diferença estatisticamente significante na concentração de CSV oral ou nasal entre os grupos. A prevalência de halitose ao teste organoléptico no grupo RSC foi $30,8 \%$, significativamente superior à do grupo controle, 7,7\% $(p=0,035)$. A prevalência de pacientes com CSV > 75 partes por bilhão (ppb) no grupo RSC foi $11,5 \%$ e a do grupo controle 19,2\% $(p=0,44)$. Conclusão: A prevalência de halitose foi significativamente maior no grupo dos pacientes com RSC, demonstrando associação entre essas condições. Não houve diferença estatisticamente significante entre os CSV de cavidade bucal ou fossas nasais entre os grupos, o que sugere que a maior prevalência de halitose se deva a compostos orgânicos voláteis, e não aos CSV nesta população. Palavras-chave: halitose; sinusite; diagnóstico; compostos de enxofre. 


\begin{abstract}
Introduction: Chronic rhinosinusitis (CRS) is an inflammatory disease of the sinus mucosa and the main symptoms are nasal blockage, rhinorrhea, facial pain and hypo/anosmia. Halitosis is the altered perception of the quality of the expired air and it causes anxiety and social embarrassment. The volatile sulphur compounds (VSC) are aminoacids degradation products and they consist in one of the causes of oral malodour. Although CRS be often cited as one of the causes of halitosis, there are no studies about the prevalence or association of this condition with CRS. Objective: to compare oral and nasal VSC levels of patients with and without CRS. Secondary objectives: to analyse oral odor of patients with and without CRS through organoleptic test and oral VSC; to analyse if halitosis prevalence is higher in patients with CRS. Methods: in this cross-sectional observational study, 26 patients with a medical diagnosis of CRS were consecutively selected from two tertiary hospitals (Brasilia University Hospital and Federal District Base Hospital) and 26 patients without CRS were selected from the same hospitals. An otolaryngologist and a dentist evaluated all patients, when collection of following data was held: demographic and clinical data, otolaryngological physical examination, breath evaluation (organoleptic test, oral and nasal VSC), sialometry and periodontal examination. The results were analyzed using Shapiro-Wilk test, Student test for independent samples and chi-square test considering $p<0.05$ for statistical significance. Results: There was no significant difference in oral or nasal VSC levels between groups. Halitosis prevalence through organoleptic test in CRS group was $30.8 \%$, significantly higher than control group, $7.7 \%(p=0.035)$. The prevalence of patients with VSC > 75 parts per billion (ppb) in CRS group was $11.5 \%$ and control group was $19.2 \% \quad(p=0.44)$. Conclusion: Halitosis prevalence was significantly higher in CRS group, showing association between these conditions. There was no statistically significant difference between oral and nasal VSC levels between groups, what suggests that the higher prevalence of halitosis be due to volatile organic compounds, but not sulfur ones, in this population. Key words: halitosis; sinusitis; diagnostic; sulfur compounds.
\end{abstract}




\section{LISTA DE ILUSTRAÇÕES}

Quadro 1. Diferenças moleculares e histológicas entre RSCcPN e RSCsPN 23

Figura 1. Realização de videoendoscopia nasal. 44

Figura 2. Padronização da distância para avaliação organoléptica 45

Figura 3. Halimeter ${ }^{\circledR}$ .46

Figura 4. Padronização da localização da extremidade do canudo e vedação labial para aferição dos CSV oral nos pacientes que possuíam fluxo nasal 47

Figura 5. Padronização da localização da extremidade do canudo e ausência de vedação labial para aferição dos CSV oral nos pacientes respiradores orais 47

Figura 6. Padronização da localização da extremidade do canudo em fossa nasal e vedação do vestíbulo nasal para aferição do CSV nasal 48

Figura 7. Padronização da localização da extremidade do canudo em fossa nasal sem vedação do vestíbulo nasal nos pacientes respiradores orais para aferição do CSV nasal 48

Figura 8. Posição do paciente para coleta do fluxo salivar em repouso 49

Figura 9. Dispositivo de silicone preso a fio dental utilizado para estímulo de fluxo salivar 49 


\section{LISTA DE TABELAS}

Tabela 1 - Classificação do fluxo salivar

Tabela 2 - Características demográficas e clínicas ………………..................... 53

Tabela 3 - Informações clínicas sobre os pacientes com RSC $(n=26)$................... 54

Tabela 4 - Comparação da halimetria e sialometria entre os grupos ...................... 55

Tabela 5 - Respostas afirmativas às perguntas sobre o hálito ………………..... 55 


\section{LISTA DE ABREVIATURAS E SIGLAS}

AAS

$\mathrm{CH}_{3} \mathrm{SH}$

$\left(\mathrm{CH}_{3}\right)_{2} \mathrm{~S}$

CID

cm

Cov

CSV

DREA

EPOS

EUA

EVA

FFNN

GA ${ }^{2}$ LEN

$\mathrm{H}_{2} \mathrm{~S}$

ICAR:RS

$\lg$

IL

PAMP

PRR

RSC

$\mathrm{RSCcPN}$

RSCsPN

SF-36

SNOT-22

Th

TLR

TNF- $\alpha$

TO

Treg
Ácido Acetilsalicílico

Metilmercaptano

Dimetilsulfeto

Código Internacional de Doenças

Centímetros

Compostos Orgânicos Voláteis

Compostos Sulfurados Voláteis

Doença Respiratória Exacerbada pela exposição ao Ácido acetilsalicílico

European Position Paper on Rhinosinusitis and Nasal Polyps

Estados Unidos da América

Escala Visual Analógica

Fossas Nasais

Global Allergy and Asthma Network of Excellence

Sulfeto de Hidrogênio

International Consensus Statement on Allergy and Rhinology:

Rhinosinusitis

Imunoglobulina

Interleucina

Pathogen-Associated Molecular Patterns

Pattern Recognition Receptors

Rinossinusite Crônica

Rinossinusite Crônica com Polipose Nasal

Rinossinusite Crônica sem Polipose Nasal

Short-Form 36 Health Survey

Sino-Nasal Outcome Test

$T$ helper

Toll-like receptors

Tumoral Necrosis Factor a

Teste Organoléptico

$T$ reguladora 


\section{SUMÁRIO}

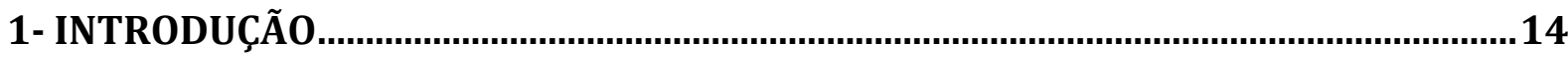

2. REVISÃO DA LITERATURA......................................................................................16

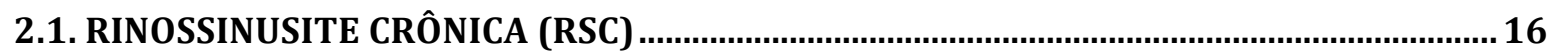

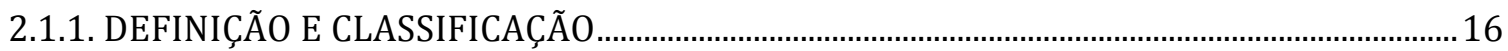

2.1.2. DEFINIÇÃO DE RINOSSINUSITE CRÔNICA: DOENÇA OU SÍNDROME? ...............................17

2.1.3. EPIDEMIOLOGIA ........................................................................................................... 18

2.1.4. AVALIAÇÃO DA GRAVIDADE DA DOENÇA E IMPACTO NA QUALIDADE DE VIDA........19

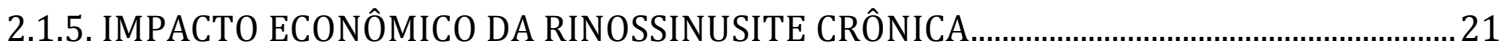

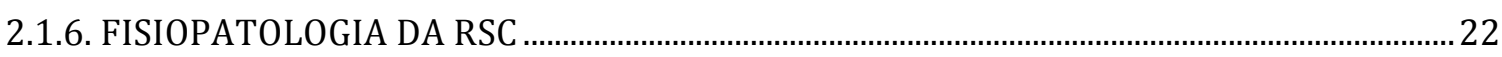

2.1.6.1. DIFERENCIAÇÃO INFLAMATÓRIA E ASPECTOS IMUNOLÓGICOS .............................................. 23

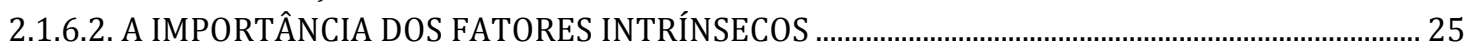

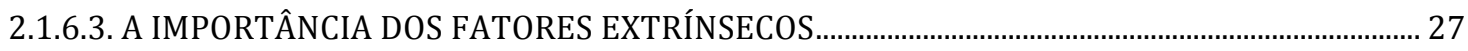

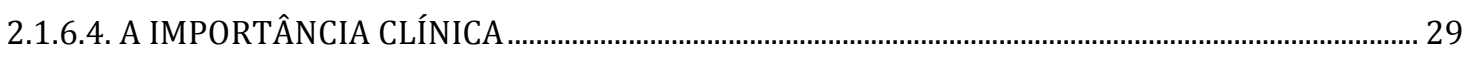

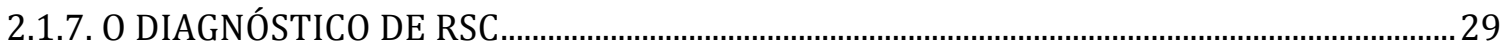

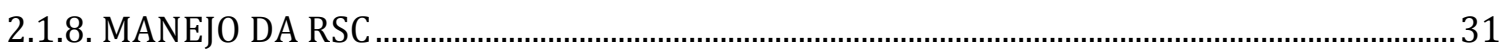

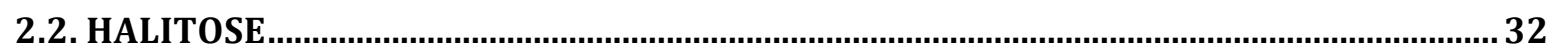

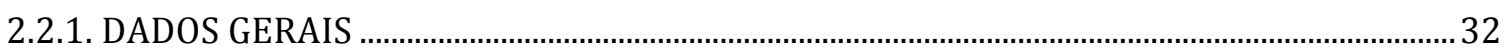

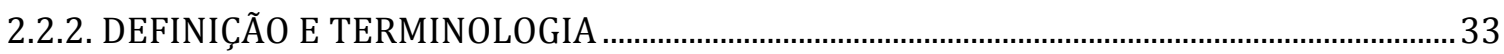

2.2.3. EPIDEMIOLOGIA E IMPACTO NA QUALIDADE DE VIDA..................................................... 34

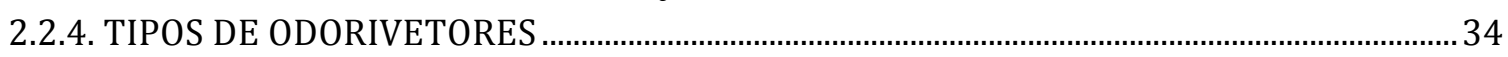

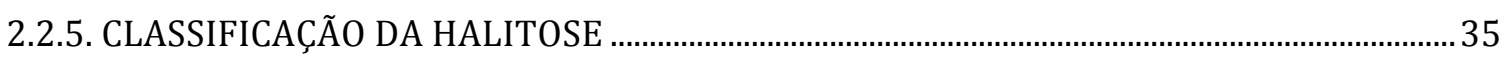

2.2.6. DIAGNÓSTICO

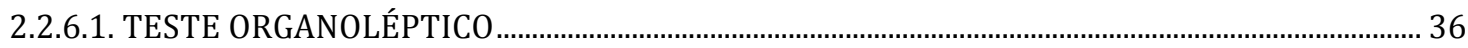

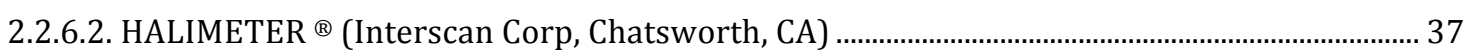

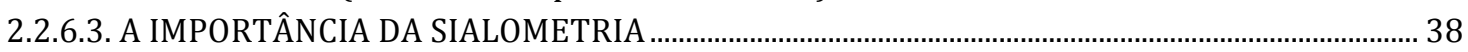

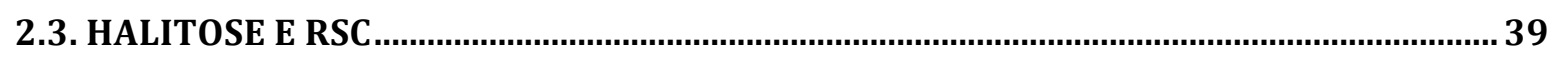

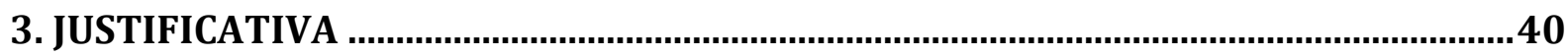

4. OBJETIVOS

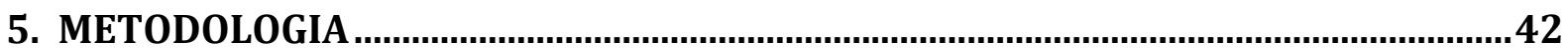

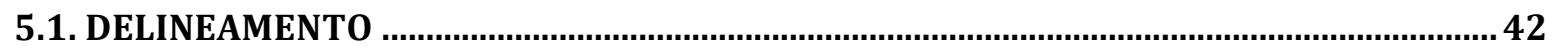

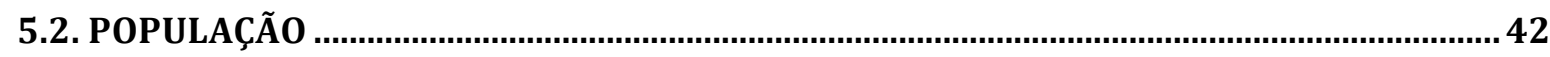

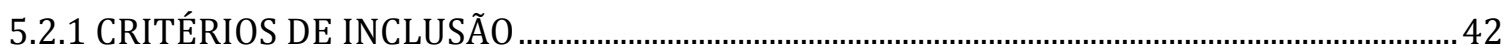

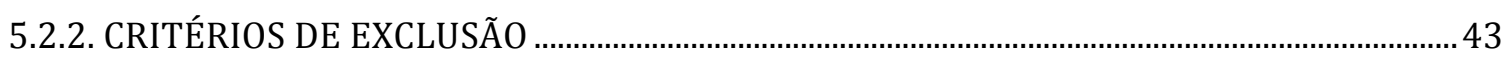

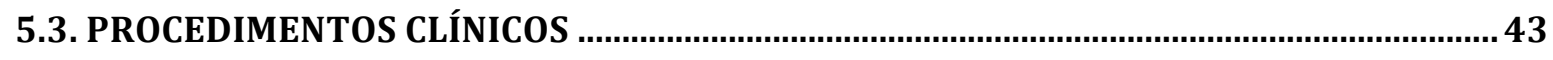

5.3.1. COLETA DE DADOS DEMOGRÁFICOS E AVALIAÇÃO NASOSSINUSAL ................................ 43

5.3.2. HALIMETRIA

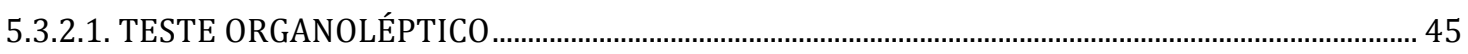

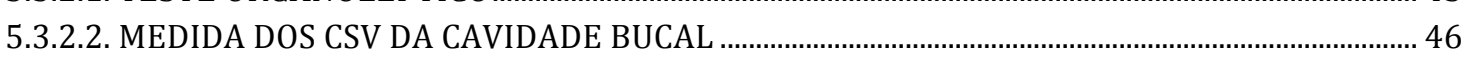

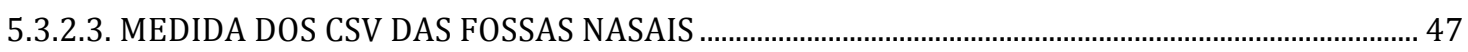

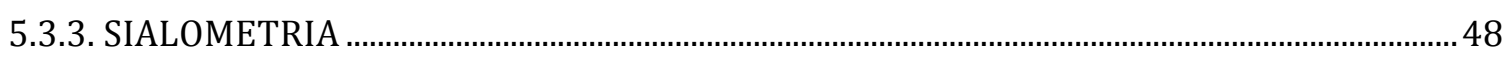

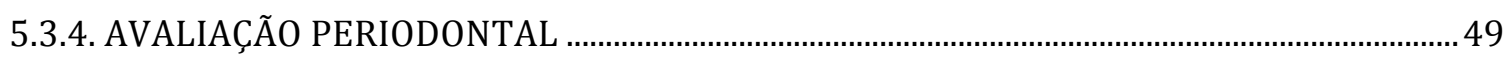

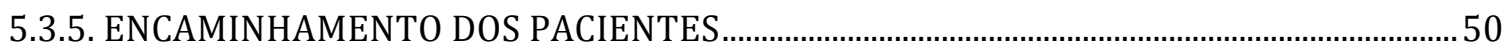

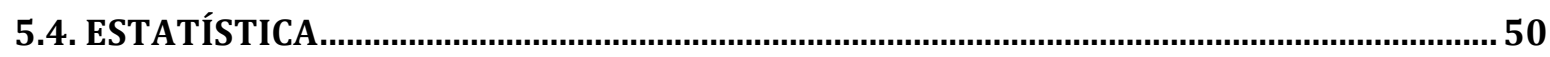

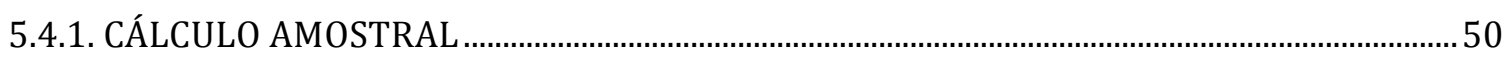




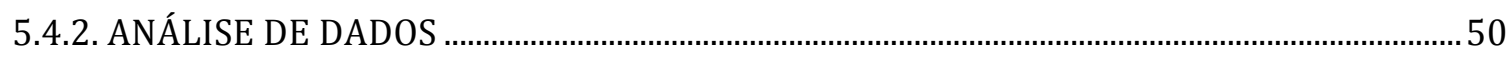

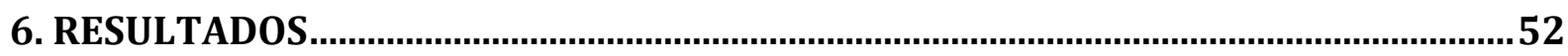

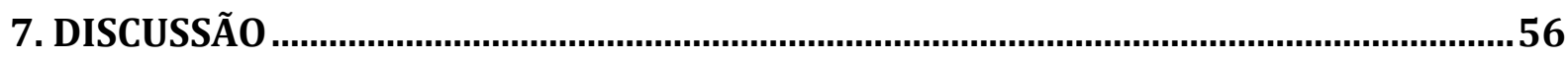

8. CONCLUSÃO

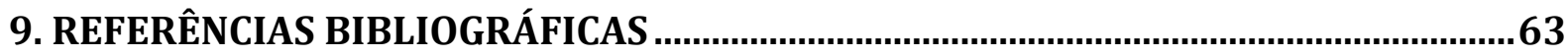

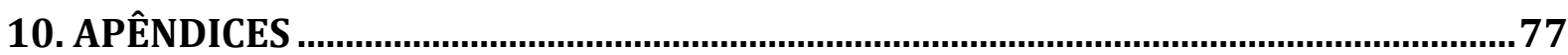

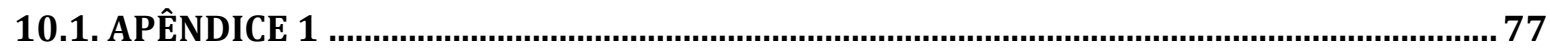

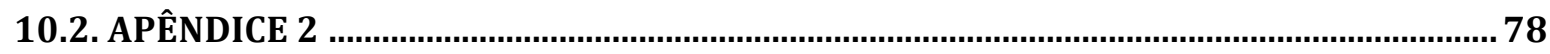

11. ANEXOS

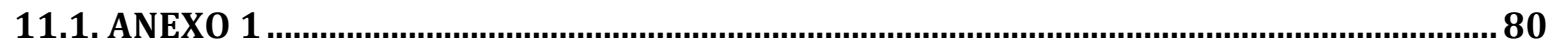

11.2. ANEXO $2 \ldots \ldots \ldots$ 


\section{1- INTRODUÇÃO}

A rinossinusite é uma doença inflamatória imunológica que acomete a mucosa das fossas nasais e das cavidades paranasais e vem crescendo em prevalência e incidência. É uma das principais razões para a prescrição de antibióticos e perda de produtividade laboral. Estima-se que cerca de $135 \mathrm{em}$ cada 1000 pessoas (ou um total de 31 milhões de pessoas) sejam afetadas por essa doença nos Estados Unidos da América (EUA) a cada ano, resultando em um custo anual de US $\$ 8,6$ bilhões. ${ }^{1-3}$

A última década assistiu ao desenvolvimento de uma série de diretrizes, documentos de consenso e tomadas de posição sobre o diagnóstico, a epidemiologia e o tratamento da rinossinusite crônica (RSC) com ou sem polipose nasal. As propostas mais adotadas atualmente são do European Position Paper on Rhinosinusitis and Nasal Polyps (EPOS) ${ }^{4}$ e do International Consensus Statement on Allergy and Rhinology: Rhinosinusitis (ICAR:RS). ${ }^{5}$

A RSC pode estar relacionada a diversos fatores, como fatores intrínsecos das vias aéreas superiores, distúrbios imunológicos, presença de biofilmes bacterianos e alterações genéticas do hospedeiro. ${ }^{6}$

Já a halitose pode ser definida como a percepção da qualidade alterada do odor do ar expirado. ${ }^{7-9}$ Estima-se que mais de 85 milhões de pessoas no planeta sofram de halitose, sendo sua prevalência estimada em $10-30 \%$ entre os norteamericanos e os chineses e em $15 \%$ na população brasileira. ${ }^{10,11}$ Estudos recentes têm demonstrado que, na maioria dos casos, a halitose encontra-se intimamente relacionada à degradação de aminoácidos contendo enxofre em sua composição (metionina, cisteína e cistina) por bactérias anaeróbias Gram-negativas presentes na cavidade bucal. A decomposição de tais aminoácidos resulta na formação dos denominados compostos sulfurados voláteis (CSV). ${ }^{8,12}$

As doenças da cavidade bucal respondem por $90 \%$ dos casos de halitose (a chamada halitose intraoral). ${ }^{10} \mathrm{~A}$ maioria dos fatores etiológicos bucais é decorrente da decomposição de aminoácidos, putrefação de sangue, saliva e de tecidos, além da diminuição do fluxo salivar, condições essas que resultam na liberação de CSV e compostos orgânicos voláteis (COV). ${ }^{10}$

A halitose extraoral responde por $10 \%$ do total dos casos de halitose $\mathrm{e}^{10} \mathrm{e}$ inclui infeções e doenças crônicas do sistema respiratório, doenças gastrointestinais, 
metabólicas e falências hepática e renal. As causas mais comuns de halitose de origem respiratória são as amigdalites, adenoidites e as RSC.,12

Existem poucos dados na literatura a respeito da presença de halitose nos pacientes com RSC, o que impossibilita determinar sua real prevalência, bem como uma possível associação entre halitose e RSC. Da mesma forma, muitos pacientes com halitose extraoral relatam ser portadores de rinossinusite sem ter o diagnóstico firmado por um profissional da área médica. Em virtude da importante redução da qualidade de vida e prejuízos ao convívio social do paciente com halitose, é fundamental ter conhecimento da manifestação da halitose no tratamento da RSC de forma a devolver ao paciente não somente o pleno conforto nasossinusal e orofaríngeo a partir da terapêutica empregada, mas também seu restabelecimento social. 


\section{REVISÃO DA LITERATURA}

\subsection{RINOSSINUSITE CRÔNICA (RSC)}

\subsubsection{DEFINIÇÃO E CLASSIFICAÇÃO}

A rinossinusite é uma doença que acarreta importantes repercussões financeiras sobre o sistema de saúde e a capacidade laborativa da população em que incide. ${ }^{13}$ Cabe a diferentes especialistas médicos (otorrinolaringologistas, alergologistas, pneumologistas, clínicos e pediatras) o diagnóstico desta condição, portanto sua definição é imperativa.

A RSC em adultos é definida como inflamação da mucosa nasossinusal com duração igual ou superior a 12 semanas caracterizada por:

a) Dois ou mais dos seguintes sinais/sintomas:

a.1) Obstrução/congestão nasal;

a.2) Rinorréia anterior/posterior;

a.3) Dor/pressão facial;

a.4) Hipo/anosmia

e

b) Sinais endoscópicos, como:

b.1) Pólipos nasais;

b.2) Descarga mucopurulenta proveniente primariamente do meato médio;

b.3) Edema mucoso ou obstrução primária do meato médio;

e/ou

c) Alterações tomográficas na mucosa dos seios paranasais ou no complexo ostiomeatal. ${ }^{4,5}$

A presença isolada dos sintomas possui alta sensibilidade, mas baixa e inaceitável especificidade. Portanto, para correto diagnóstico, os sintomas devem ser acompanhados de achados consistentes com inflamação ou alterações mucosas ao exame endoscópico e/ou de imagem. ${ }^{14}$ 
O termo "rinossinusite" é empregado no lugar de "sinusite" desde 1996, quando a Força Tarefa para Rinossinusite (Task Force on Rhinosinusitis) ${ }^{15}$, uma equipe multidisciplinar apoiada pela Academia Americana de Otorrinolaringologia e Cirurgia Cérvico-Facial, concordou na substituição do termo para salientar a estreita relação entre o nariz e os seios paranasais e as semelhanças quanto ao seu revestimento mucoso morfológica e fisiologicamente. Desde então, inúmeras diretrizes e revisões acerca do tema corroboraram a noção de que "sinusite" é quase sempre precedida por ou acompanhada de "rinite"., $4,6,15$ Sabe-se ainda que o padrão de mediadores inflamatórios na cavidade nasal é semelhante ao do interior dos seios paranasais. ${ }^{17,18} \mathrm{Tal}$ fato respalda a teoria de inflamação contígua da mucosa do bloco anatômico-funcional composto pelas cavidades nasais em conjunto com os seios paranasais e justifica o uso do termo "rinossinusite". ${ }^{18}$

\subsubsection{DEFINIÇÃO DE RINOSSINUSITE CRÔNICA: DOENÇA OU SÍNDROME?}

Levando em consideração os diferentes fenótipos clínicos e padrões inflamatórios da RSC, o termo "rinossinusite crônica" engloba vários estados de doença inflamatória das cavidades nasossinusais. Com base na análise clínica e/ou radiológica, a RSC é geralmente dividida em RSC sem pólipos nasais (RSCsPN) e RSC com pólipos nasais (RSCcPN). Além destes dois principais fenótipos descritos, na prática clínica é comum se deparar com outros fenótipos associados à variedade de sintomas nestes pacientes e presença ou ausência de doença brônquica concomitante. ${ }^{4,14}$ Considerando a diversidade de fatores etiológicos associados, é compreensível a existência de diferentes fenótipos de uma mesma doença. ${ }^{5}$

Uma vasta gama de padrões inflamatórios pode ter ação sinérgica a anormalidades mucociliares e/ou estruturais para dar origem ao desenvolvimento de RSC. A etiologia multifatorial da RSC, envolvendo fatores genéticos, influências ambientais, fatores ocupacionais, infecção, alergia, alterações imunológicas e doenças sistêmicas, levou à recente tentativa de definir endotipos da doença.

A RSC foi classificada em diferentes padrões de resposta inflamatória, como T helper 1 (Th1 - predomínio de ação neutrofílica), e T helper 2 (Th2 - predomínio da atividade inflamatória por eosinófilos). ${ }^{19}$ Vários mediadores inflamatórios específicos têm sido associados com a RSC e os efeitos benéficos dos novos tratamentos com agentes biológicos, como anti-interleucina 5 (IL-5), e anti-imunoglobulina $\mathrm{E}$ (IgE), 
entre outros, corroboram sua importância. ${ }^{5}$ Deve-se, no entanto, ter em mente que estes padrões inflamatórios se combinam em diferentes proporções em cada indivíduo.

Portanto, avaliada em conjunto, a RCS representa uma condição com diferentes fenótipos e endotipos, que ainda necessitam de maiores esclarecimentos. O desafio para o futuro é entender, em cada paciente de forma individualizada, os diferentes fatores etiológicos responsáveis pelo desenvolvimento da doença, bem como o padrão individualizado de reação inflamatória. ${ }^{5}$

\subsubsection{EPIDEMIOLOGIA}

A revisão da literatura disponível atualmente ilustra a escassez de informações precisas sobre a epidemiologia da RSC. Os dados epidemiológicos, além de raros, são conflitantes entre si na medida em que diferem os critérios diagnósticos adotados. Algumas pesquisas foram realizadas por meio de entrevistas domiciliares ou telefônicas, em que a doença foi autorreferida pelo entrevistado; outras, em instituições de saúde mediante levantamento de dados registrados pelo médico, com auxílio do Código Internacional de Doenças (CID), o que torna difícil realizar comparações. ${ }^{20,21}$

A autodenominação pelos pacientes de serem portadores de RSC em respostas a questionários promove estimativas errôneas sobre a prevalência da doença pelos seguintes motivos: ${ }^{21}$

a) a informação do diagnóstico é fornecida pelo indivíduo sem confirmação médica;

b) o indivíduo pode se autodenominar portador do diagnóstico de RSC devido a sintomas que o sugerem ser portador da doença, mas também são comuns a outras doenças;

c) o indivíduo pode ter recebido este diagnóstico erroneamente; ou,

d) o indivíduo pode ter tido rinossinusite aguda tratada ou resolvida no passado mas continua a referir este diagnóstico.

O recente estudo multicêntrico GA ${ }^{2}$ LEN (Global Allergy and Asthma Network of Excellence $)^{22}$ permitiu estimar uma prevalência da RSC de $10,9 \%$ na população europeia por meio de questionários enviados por correio. Nos EUA, o estudo 
realizado pelo Centro Nacional de Estatísticas em Saúde (National Center for Health Statistics - NCHS), mediante inquéritos populacionais domiciliares, estimou a prevalência de diagnóstico autorreferido de rinossinusite em $13 \%$ da população. ${ }^{23} \mathrm{~A}$ partir da análise da pesquisa do painel de despesas em saúde (Medical Expenditure Panel Survey - MET), a prevalência de RSC neste país foi estimada em 4,9\%. ${ }^{24}$ Chen e colaboradores ${ }^{25}$ estimaram uma prevalência de $5 \%$ no Canadá e Shashy e colaboradores $^{21}$ estimaram que aproximadamente $2 \%$ da população na cidade de Olmsted (Minnesota, EUA) apresentaria o diagnóstico de RSC segundo a análise dos registros médicos baseados no CID. Pilan e colaboradores, por meio de questionários populacionais com critérios clínicos estabelecidos pelo EPOS, estimaram a prevalência de rinossinusite crônica na cidade de São Paulo em 5,5\%. ${ }^{20}$ Desta forma, a prevalência de RSC varia entre $2 \%$ a $13 \%$ nos principais estudos populacionais. $^{20-25}$

\subsubsection{AVALIAÇÃO DA GRAVIDADE DA DOENÇA E IMPACTO NA QUALIDADE DE VIDA}

Existe crescente aceitação na literatura que a visão do paciente é essencial na promoção da saúde. Assim, durante a avaliação clínica do paciente com RSC, é imperativo graduar objetivamente a gravidade das queixas autoreferidas. Além disso, é fundamental verificar o impacto que a doença provoca na qualidade de vida, de forma a obter melhor direcionamento da terapêutica e padronização do seguimento clínico. ${ }^{4,5}$

A escala visual analógica (EVA) é uma escala unidirecional amplamente empregada na prática clínica. Trata-se de uma linha de 10 centímetros $(\mathrm{cm})$ de comprimento com uma extremidade marcada em 0 definida como ausência de sintoma e a outra marcada em 10 definida como sintoma em intensidade máxima em que o paciente assinala o ponto correspondente à intensidade de seu sintoma. Mede-se, então, a distância em $\mathrm{cm}$ do 0 ao ponto assinalado para se atribuir uma medida objetiva (número) ao dado subjetivo (sintoma). ${ }^{26} \mathrm{Na}$ RSC, sabe-se que uma pontuação superior a 5 na EVA já é suficiente para afetar a qualidade de vida do paciente. ${ }^{4,5}$ Pode-se utilizar a EVA para cada sintoma da RSC individualmente ou para o conjunto dos sintomas, o que caracterizará a gravidade da doença de acordo com a classificação: ${ }^{4}$ 
- $\quad$ Leve: EVA 0-3

- $\quad$ Moderada: EVA >3-7

- $\quad$ Grave: EVA>7-10

Da mesma forma, os questionários de qualidade de vida têm sido frequentemente utilizados em ensaios clínicos para determinar o impacto promovido por uma intervenção ou para avaliar os resultados dos serviços de saúde. O foco de cada questionário pode estar voltado para o estado de saúde ou para a qualidade de vida ${ }^{27} \mathrm{O}$ estado de saúde pode ser descrito por limitações físicas, funcionais ou de experiências sociais relatadas pelos pacientes. A descrição de qualidade de vida, no entanto, é vista como uma experiência única e pessoal, que reflete não apenas o estado de saúde, mas também outros fatores e circunstâncias da vida do paciente. ${ }^{28}$ De acordo com esta definição, médicos e outros profissionais da saúde podem descrever o estado de saúde de cada indivíduo, mas apenas o paciente, individualmente, pode descrever sua própria qualidade de vida. ${ }^{28}$

Questionários gerais, como o Short-Form 36 Health Survey $(\mathrm{SF}-36)^{29}$, permitem comparação entre diferentes situações e tratamentos, além de poder determinar o impacto de diferentes doenças em grupos de pacientes. Por outro lado, questionários específicos para a doença identificam mais facilmente os sintomas importantes, focam a consulta e providenciam um registro clínico útil, podendo ser utilizados para definir objetivos de tratamento. Além disso, são mais sensíveis a pequenas mudanças após intervenções do que os questionários gerais, motivos pelos quais são preferíveis. ${ }^{30}$

O questionário SNOT-22 (sigla em inglês de Sino-Nasal Outcome Test, teste de desfecho sinonasal) tem a vantagem de combinar questões específicas de doença nasossinusal com questões de saúde geral, que podem ser avaliadas isoladamente ou em conjunto, tanto no pré como pós-operatório. ${ }^{31}$ Trata-se de 22 questões-problema às quais o paciente deve atribuir um escore de 0 a 5 , sendo que escores maiores significam problemas maiores. Ao fim, faz-se a somatória da pontuação, podendo o escore final variar entre 0 e $110 .^{31}$ O SNOT-22 já foi traduzido, validado e adaptado para a realidade brasileira. ${ }^{32}$ 


\subsubsection{IMPACTO ECONÔMICO DA RINOSSINUSITE CRÔNICA}

Não há fontes brasileiras de dados relativos aos custos com a RSC. Nos EUA, os custos diretos com esta doença são levantados em diferentes níveis com base em coortes institucionais, análises de bancos de dados de seguradoras e análises de dados nacionais relativos a custos em saúde.

Coortes institucionais, mais comumente de centros médicos acadêmicos norte-americanos e canadenses, quantificaram o custo em saúde de pacientes com RSC entre US\$ 921 a 1220 por paciente-ano. ${ }^{2,33}$ Estes dados, no entanto, apresentam viés em relação à maior gravidade de doença. Os custos não estão relacionados apenas à terapia medicamentosa, mas também ao tratamento cirúrgico. ${ }^{5}$ Estudos econômicos demonstram o valor de uma cirurgia endoscópica funcional para os seios da face variando entre US\$3500 (no Canadá) a US\$7700 por caso (nos EUA). ${ }^{13,34}$ A presença ou ausência de pólipos também influencia diretamente o custo de tratamento destes pacientes. Pacientes com polipose nasossinusal recorrente após cirurgia primária demonstraram maior custo em saúde por ano (US\$866) quando comparados aos pacientes sem polipose nasal (US\$570) ou polipose cirurgicamente abordada pela primeira vez (US\$565). ${ }^{35}$

Em contraste com os custos diretos de cuidados em saúde, os custos de saúde indiretos de RSC incluem os custos sociais relacionados com a ausência do trabalho (absenteísmo), diminuição da produtividade do trabalho enquanto doente (presenteísmo) e outras formas de perda de produtividade (por exemplo, a vida domiciliar). ${ }^{5}$ Em um estudo norte-americano domiciliar de base nacional, entre os $15,2 \%$ daqueles que relataram rinossinusites agudas ou crônicas, anualmente, 5,7 dias de trabalho foram perdidos versus 3,7 para aqueles sem esta condição, com significância estatística. ${ }^{1}$ Anualmente, isso se traduz em 61,2 milhões potenciais dias de trabalho perdidos por ano entre os adultos nos EUA e uma perda de produtividade no trabalho estimado de US\$ 3,79 bilhões. ${ }^{1,36}$

A carga de custo indireto global da RSC é substancial e se relaciona com a gravidade subjacente da doença. Em um estudo norte-americano com pacientes com RSC refratária ao tratamento, Rudmik e colaboradores ${ }^{37}$ descreveram taxas anuais médias de absentismo de 24,6 dias por ano e presenteísmo de 38,8 dias por ano, com um custo anual da produtividade global de US\$ 10.077 por paciente. 
Os custos indiretos da RSC não estão relacionados apenas com o trabalho. Em uma amostra americana nacionalmente representativa, Bhattacharyya e colaboradores $^{24}$ determinaram limitações de atividade em 13,3\%, limitações de trabalho em 12\%, limitações sociais em $9 \%$ e limitações cognitivas em $6 \%$ dos 225,1 milhões de pacientes com RSC.

Por definição, os pacientes com RSC vão sofrer com alguma combinação dos sintomas nasossinusais cardinais, incluindo congestão nasal, rinorreia, pressão/dor facial e hipo/anosmia. A descrição dos sintomas nasossinusais individuais e gravidade global da doença é muitas vezes feita usando escalas analógico visuais ou questionários específicos de qualidade de vida, como o SNOT-22 $2^{32}$. Entretanto, o impacto da RSC muitas vezes se estende além da região nasossinusal e pode ter efeitos profundos sobre o bem-estar funcional e qualidade de vida geral dos pacientes. Vários estudos têm explorado o comprometimento da qualidade de vida provocado pela RSC e comparado os resultados com a pontuação de pacientes com outras doenças crônicas. Soler e colaboradores ${ }^{38}$ avaliaram o estado de saúde de 230 pacientes com RSC usando adaptações do instrumento Short Form 6D (SF-6D), sendo a média 0,65 ( 0 = pior estado de saúde possível, 1 = saúde perfeita). Este escore foi pior do que o que tem sido relatado para insuficiência cardíaca congestiva, doença pulmonar obstrutiva crônica e doença de Parkinson. ${ }^{38}$ Estudos semelhantes foram realizados demonstrando comprometimento grave na qualidade de vida geral e bem-estar utilizando questionários validados como o SF-36 e Euro Quality of life 5 Dimension (EQD-5). ${ }^{39}$ Quando as respostas de pacientes com RSC são examinadas em detalhe, as manifestações extrasinusais mais comuns da doença incluem fadiga, dores no corpo, distúrbios no sono e depressão. ${ }^{40-42}$

\subsubsection{FISIOPATOLOGIA DA RSC}

A fisiopatogenia da RSC ainda não é totalmente conhecida. Vários estudos têm sido publicados nos últimos anos relacionados a este tópico, com o objetivo de tentar compreender um pouco melhor o motivo do desenvolvimento dessa doença, qual a população mais suscetível e, finalmente, qual o melhor tratamento. ${ }^{4,5}$

A RSC é fenotipicamente dividida em RSCcPN e RSCsPN. Essa divisão se baseia na existência de pólipos nas fossas nasais e/ou seios paranasais, que podem ser visualizados a olho nu, por meio da rinoscopia anterior, ou com o auxílio de 
endoscopia nasal. Sabe-se atualmente que a presença de pólipos não é uma particularidade apenas fenotípica, mas que existe uma diferenciação de mediadores moleculares entre as duas entidades. ${ }^{5}$

\subsubsection{DIFERENCIAÇÃO INFLAMATÓRIA E ASPECTOS IMUNOLÓGICOS}

A RSCsPN é caracterizada pelo infiltrado neutrofílico, com aumento de fibrose tecidual e depósito de colágeno no estroma; a membrana basal está espessada e não há a formação de pseudocistos. ${ }^{43} \mathrm{~A}$ RSCcPN está associada ao acúmulo de albumina e edema no estroma, à formação de pseudocistos, além de espessamento da membrana basal; no epitélio, evidenciam-se aumento de células caliciformes e presença de epitélio metaplasiado. ${ }^{43}$ Acreditava-se que essas alterações histológicas fossem explicadas essencialmente por alterações da imunidade adaptativa. Essa é uma resposta especificamente relacionada a antígenos e coordenada por linfócitos, especialmente pela produção de citocinas. Na RSCcPN há a amplificação das respostas inflamatórias, tanto Th1 como Th2, além de diminuição de resposta $T$ reguladora (Treg) ${ }^{44,45} \mathrm{~A}$ resposta Treg é essencialmente a moduladora do processo inflamatório; quando diminuída, o processo inflamatório deixa de ser localizado, sendo muito mais amplo. Os seus principais marcadores Fox-p3 e fator de crescimento transformador $\beta$ (TGF- $\beta$ ) estão diminuídos na RSCCPN, porém mantidos na RSCsPN. ${ }^{44,46}$ Acredita-se que a diminuição desses fatores na RSCcPN seja determinante para a dificuldade de se conter o processo inflamatório neste subtipo de RSC.

As principais diferenças histológicas e moleculares entre RSCcPN e RSCsPN estão listadas no Quadro 1.

Quadro 1. Diferenças moleculares e histológicas entre RSCcPN e RSCsPN

$\begin{array}{lcc} & \text { RSCcPN } & \text { RSCsPN } \\ \text { Alteração tecidual predominante } & \text { Edema } & \text { Fibrose } \\ \text { Resposta inflamatória } & \text { Predomínio Th2 } & \text { Predomínio Th1 } \\ \text { Citocinas } & \text { Aumento de IL-4, IL-5 } & \text { Aumento de IL-6, IL-8, TNF-a } \\ \text { Padrão inflamatório } & \text { Eosinofílico } & \text { Neutrofílico } \\ \text { Resposta Treg } & \text { Diminuída } & \text { Normal }\end{array}$


Na população europeia e americana (incluindo o Brasil), existe polarização da resposta pró-inflamatória para o Th2, com aumento de IL-5, IL-4, IL-13. ${ }^{19,47,48}$ Entre esses fatores, o que merece maior destaque é a IL-5, por ser uma citocina produzida essencialmente por eosinófilos, com função essencial de recrutar e aumentar a sobrevida destas células. Assim, a IL-5 é responsável pela perpetuação da eosinofilia tecidual. ${ }^{44,49}$ Além disso, está associada a maior risco de asma ${ }^{49}$ e outras comorbidades, como doença respiratória exacerbada pela exposição ao ácido acetilsalicílico (DREA) ${ }^{47}$ e pior prognóstico pós-operatório. ${ }^{49}$ Isso ocorre porque os eosinófilos produzem e liberam no tecido proteínas com alto poder de lesão tecidual, como a proteína catiônica eosinofílica (PCE) e os leucotrienos. ${ }^{47,48}$

$\mathrm{Na}$ população asiática e nos pacientes com fibrose cística, o padrão inflamatório predominante é o neutrofílico, mediado especialmente por moléculas de padrão Th1 e Th17. ${ }^{4}$ As principais citocinas envolvidas nesse processo são IL-8, Interferon-Y (IFN- Y), mieloperoxidase (MPO) e interleucina-1 $\beta$ (IL-1 $\beta$ ). ${ }^{19,48}$ A IL-1 $\beta$ tem sua importância por estar associada a pior resposta ao tratamento com corticosteróide tópico e a pior prognóstico pós-operatório, apesar de não ser específica para os padrões inflamatórios Th1 ou Th2. ${ }^{19}$

Assim, os estudos em imunidade adaptativa foram importantes para estabelecer a diferenciação entre as RSC com e sem pólipos, mas não explicam o motivo de alguns pacientes desenvolverem uma ou outra forma da doença. Estudos mais recentes têm creditado à resposta de imunidade inata o elo entre lesão tecidual epitelial (iniciador do processo inflamatório) e ativação da cascata inflamatória adaptativa. $^{50}$

Quando o epitélio está lesado, os padrões moleculares associados a patógenos (PAMPs, do inglês pathogen-associated molecular patterns), que podem ser patógenos, antígenos, células necróticas ou outros, ligam-se aos receptores de reconhecimento-padrão (PRRs, do inglês pattern recognition receptors), presentes na membrana celular e no citoplasma das células epiteliais. Entre os PRRs, os mais conhecidos atualmente são os toll-like receptors (TLRs) e os NOD-like receptors (NLRs). ${ }^{47}$

Existem no epitélio nasal mais de 10 TLRs, sendo cada um deles específico para um agente. TLR-2, por exemplo, se ativa em contato com bactérias Grampositivas e fungos, enquanto TLR-3 se ativa em contato com ds-RNA (presente em 
vírus) e TLR-4 em contato com lipopolissacarídeos presentes em bactérias Gramnegativas. ${ }^{51}$ Uma vez ligados aos PAMPs, os TLRs induzem a secreção de proteínas no muco nasal (como lisozimas e lactoferrina) ${ }^{19}$, citocinas e quimiocinas. ${ }^{51}$

A produção desses receptores TLRs está alterada em pacientes com RSC de forma diferenciada em seus subtipos. Enquanto a RSCsPN apresenta aumento da expressão de TLR-2 e TLR-4, os pólipos nasais apresentam diminuição da TLR-2 e TLR-9. ${ }^{47,52}$ Essa alteração de perfil de TLR na RSCcPN demonstra ainda associação com a recorrência da doença, de forma que pacientes com menor expressão de TLR-2 e TLR-9 exibem recidiva mais precoce. ${ }^{52}$

Algumas citocinas ajudam na diferenciação de padrão inflamatório das células dendríticas e dos linfócitos. Por exemplo, as citocinas IL-33, IL-25 e thymic stromal lymphoprotein (TSLP), produzidas pelo epitélio, induzem um padrão inflamatório Th2. ${ }^{47,51}$ A expressão de IL-33 está aumentada na RSC, tem relação direta com o grau de eosinofilia no tecido e está amplificada nos pacientes pouco responsivos ao tratamento. ${ }^{53}$

Acredita-se que o padrão inflamatório na RSC dependa da combinação de fatores intrínsecos (genéticos do hospedeiro) e extrínsecos (exposição a fatores externos). ${ }^{54}$

\subsubsection{A IMPORTÂNCIA DOS FATORES INTRÍNSECOS}

Um exemplo da importância da genética na RSC é o gene cystic fibrosis transmembrane receptor (CFTR). Mutações neste gene estão relacionadas à fibrose cística. A homozigose da mutação $\Delta \mathrm{F} 508$ está relacionada à presença de pólipos nasais e de fibrose cística na população brasileira. ${ }^{55}$ No entanto, mutações mais sutis têm sido relacionadas à RSC, mesmo na ausência de fibrose cística. ${ }^{56}$

Existem outras associações de polimorfismos em imunidade inata e RSC. Como exemplos citam-se os polimorfismos de TLR-2 rs3804099 e rs380410048, cuja presença está aumentada na RSCcPN. ${ }^{57}$ Ainda, o alelo G do polimorfismo G$174 \mathrm{C}$ da IL-6 apresentou associação com RSC com pólipos nasais e asma. ${ }^{58}$ A IL-33 também foi associada à RSC com pólipos pelo seu alelo A do polimorfismo rs3939286. ${ }^{59}$

Outra alteração gênica recentemente relacionada à RSC é a de receptores gustatórios. ${ }^{59,60}$ Credita-se a essa variedade de receptores a capacidade de 
proteção do tecido contra agentes externos, em especial bactérias. Nos pacientes com RSC, os receptores T2R (para gosto amargo) estão diminuídos, ao passo que os T1R (para gosto doce) estão aumentados. ${ }^{60}$ Essa variabilidade gênica esteve mais suscetível à diminuição de função de imunidade inata e maior suscetibilidade de infecção bacteriana. ${ }^{60}$

Verifica-se ainda, que alterações no batimento ciliar da mucosa nasossinusal têm implicação na etiopatogenia da RSC. O batimento ciliar se dá de forma unidirecional a fim de mover o muco para o óstio sinusal e daí para naso e orofaringe, a fim de que seja expectorado ou deglutido. ${ }^{61}$ Os pacientes com RSC podem ter disfunção no batimento ciliar provocada por efeitos diretos dos microorganismos ou pela resposta inflamatória exacerbada. A estase mucociliar é um achado frequente na RSC e pode abrigar a infecção e estimular a secreção de mediadores inflamatórios, constituindo portanto um meio de perpetuação da doença ${ }^{62}$ Os cílios de pacientes com RSC apresentam resposta diminuída a agentes que sabidamente aumentam sua função em controles. ${ }^{63,64}$ Toxinas de microorganismos (como a piocianina, produzida pela P.aeruginosa) e fatores inflamatórios (TNF- $\alpha, I L-1 \beta, I L-5$ e IL-8) reduzem a resposta ciliar a estímulos mecânicos e podem causar perdas ou anomalias ciliares em um cenário de cronicidade. $^{65-67}$

O transporte de sódio e cloro também desempenha função na etiopatogenia da RSC prejudicando a função ciliar. Nos pacientes com RSC, a absorção de sódio pelas células da mucosa nasossinusal é aumentada, o que promove maior viscosidade do muco e portanto maior dificuldade de clearance por cílios já disfuncionantes. ${ }^{68}$ Os cílios são capazes de recuperar sua excitabilidade e atividade normal em uma mucosa nasossinusal aerada e saudável, desde que a ciliogênese não tenha sido comprometida. ${ }^{69,70}$ Assim, o tratamento da disfunção mucociliar nos pacientes com RSC envolve a recuperação da higidez da mucosa nasossinusal e controle do ambiente inflamatório associado. ${ }^{71,72}$

Variações anatômicas que comprometam o complexo óstio-meatal (como concha média bolhosa ou paradoxal, célula de Haller ou desvio septal) ou a drenagem do seio frontal foram implicadas por alguns autores como adjuvantes no desenvolvimento da RSC. ${ }^{73-76}$ A explicação fisiopatológica se pautaria no fato de que a maior dificuldade de drenagem dos seios etmoidais, maxilares e frontais 
permitiria o acúmulo de secreções e disfunções funcionais da mucosa ciliada. Entretanto, a maioria se trata de estudos antigos e que não diferenciavam os subtipos de RSC com e sem pólipos nasais. Estudos recentes demonstram não haver causalidade direta de alterações anatômicas sobre a fisiopatogenia da RSC ou piora dos escores clínicos e tomográficos. ${ }^{77-79}$ Diante de dados controversos quanto à interferência de variações anatômicas na manifestação ou progressão dos sintomas da RSC, considera-se que, uma vez instalada a doença, as alterações anatômicas descritas podem ter papel coadjuvante, mas não determinante, no prejuízo funcional do seio em questão. ${ }^{5}$

\subsubsection{A IMPORTÂNCIA DOS FATORES EXTRÍNSECOS}

Os principais agentes já relacionados à RSC, com ou sem pólipos nasais, são os agentes microbianos. No entanto, nenhum agente até o momento foi capaz de explicar a RSC de modo completo. ${ }^{5}$

Dentre os principais agentes com alta probabilidade de induzir a RSC, os vírus possuem destaque por serem capazes de associação e modificação do genoma humano e a expressão gênica. No entanto, poucos são os estudos que relacionam os vírus à RSC, sendo a maioria apenas de prevalência. ${ }^{80,81}$ Não se sabe ainda se os vírus presentes nos tecidos de RSC têm participação ativa, com replicação viral, ou se estão em forma latente. ${ }^{81}$

Os fungos já foram considerados muito importantes na patogênese da RSC, quando altos índices de fungos foram observados nestes pacientes, associado ao aumento de eosinófilos no tecido. Entretanto, outros autores não identificaram relação direta entre a RSC e a presença dos fungos, e os antifúngicos tópicos e sistêmicos não demonstraram eficácia na melhora clínica da RSC. ${ }^{82}$ Assim, acreditase que o fungo possa atuar como modulador da doença em alguns casos em específico, mas não de forma generalizada em todos os pacientes com RSC. ${ }^{83}$

Entre os agentes bacterianos, os que possuem maior prevalência na RSC são $S$.aureus, $P$.aeruginosa e bactérias anaeróbias, caracteristicamente em um perfil de microbiota diversificada. ${ }^{84}$ Merece destaque o S.aureus, não só pela sua alta frequência, mas pela sua relevância clínica: pacientes com polipose extensa têm maior frequência de S.aureus do que pacientes com RSC sem pólipos ou controles. ${ }^{85}$ 
Essa particularidade do S.aureus pode ser explicada pela capacidade de produzir exotoxinas com propriedades de superantígenos. São assim chamados pela capacidade de produção de reação inflamatória policlonal e amplificada. ${ }^{86}$ Além disso, o S.aureus tem a capacidade de permanecer viável intracelularmente na mucosa respiratória. Essa forma poderia explicar a persistência bacteriana na mucosa respiratória, em especial nos casos de doenças crônicas, propiciada pela diminuição da resposta imune adjacente à colonização intracelular. ${ }^{87}$ Recentemente, verificou-se que a presença crônica de S.aureus e superantígenos na mucosa nasossinusal pode ter a habilidade de desviar a resposta inflamatória para o tipo Th2 de forma independente. ${ }^{88}$

A persistência do processo inflamatório na RSC pode estar também associada à presença de biofilmes. ${ }^{5} \mathrm{O}$ paciente com RSC apresenta mucosa cronicamente inflamada, desnudada de cílios, fibrosada e edemaciada, com fissuras nas quais o biofilme poderia persistir cronicamente. ${ }^{89}$ Essa forma de colonização, geralmente polimicrobiana, composta por bactérias e fungos, se envolve em uma matriz polissacarídica autoproduzida que a protege da imunidade celular e humoral do hospedeiro, bem como da ação bactericida dos antibióticos. ${ }^{90}$ As infecções por biofilme tipicamente mostram sintomas recorrentes após ciclos de antibioticoterapia até que a comunidade séssil seja mecanicamente removida por meio de cirurgia. ${ }^{91} \mathrm{~A}$ presença de biofilme na cavidade nasal ou seios paranasais pode determinar uma resposta inflamatória persistente nos pacientes com RSC a partir da liberação de antígenos pelas bactérias sésseis, o que estimula a produção de anticorpos. No entanto, esses anticorpos não são efetivos em matar as bactérias dentro dos biofilmes e acabam por causar danos por imunocomplexos nos tecidos vizinhos, perpetuando a resposta inflamatória. ${ }^{89}$ Apesar de a teoria da persistência da inflamação ser aceita por inúmeros autores, sabe-se que o perfil inflamatório diante do biofilme pode variar, tendo sido descritos perfil predominantemente $T h 1^{92}$ ou Th2 ${ }^{88}$. Outro fator determinante é o tipo de patógeno presente no biofilme. A presença de S.aureus e $P$.aeruginosa está associada a pior evolução pós-operatória do que os casos em que a presença predominante nos biofilmes foi de H.influenzae ou S.epidermidis. ${ }^{93}$

Várias são as formas de manifestações nas quais as bactérias assumem potencial patogênico, assim como sua interação com o hospedeiro, de forma que é 
complexo imaginar que o mesmo cenário ocorra para todos os indivíduos. No entanto, fica evidente a possibilidade de as bactérias atuarem como moduladoras, mantenedoras ou desencadeadoras do processo inflamatório na mucosa nasossinusal.

\subsubsection{A IMPORTÂNCIA CLÍNICA}

A compreensão da fisiopatogenia da RSC com ou sem pólipos nasais é de vital importância, tendo em vista que o principal tratamento disponível atualmente para esta entidade é a modulação do processo inflamatório à base de corticosteróides. Mesmo com o uso sistematizado deste fármaco, o tratamento é considerado eficaz em torno de $60-70 \%$ da população. ${ }^{5}$

A endotipagem do indivíduo auxilia no seguimento prospectivo, de forma que pacientes que possuam aumento da expressão de IL-5, por exemplo, tenham evoluções clínicas diferentes do que pacientes com baixa expressão dessa citocina. $^{49}$

\subsubsection{O DIAGNÓSTICO DE RSC}

A definição de RSC foi realizada na seção 1 . Os sintomas associados à RSC podem ser divididos em 4 categorias: ${ }^{6}$

- $\quad$ Sintomas nasais: obstrução, rinorreia, hiposmia;

- $\quad$ Sintomas faciais: pressão ou dor facial, cefaleia;

- Sintomas orofaríngeos: otalgia, halitose, dor dentária, tosse, gotejamento posterior;

Sintomas sistêmicos: mialgia difusa, fadiga.

Neste contexto, o sintoma mais comumente apresentado é obstrução nasal. ${ }^{94}$ Os sintomas acima citados são altamente sensíveis individualmente, mas não específicos. ${ }^{95,96}$ Evidências sugerem que a combinação de dois ou mais sintomas associados a achados objetivos da doença (exame de imagem ou endoscopia nasal) aumenta substancialmente a especificidade diagnóstica e o valor preditivo positivo ${ }^{6,14,97}$ Apesar de o consenso EPOS ${ }^{4}$ utilizar critérios maiores e menores, não há consenso ou evidência se essa categorização foi baseada em prevalência, sensibilidade ou especificidade dos sintomas. Assim, o novo consenso ICAR:RS inclui a presença de 2 dos 4 sintomas cardinais para diagnóstico (obstrução nasal, 
dor/pressão facial, rinorreia e hiposmia) sem, entretanto diferenciá-los em maiores ou menores. ${ }^{5}$ Os demais sintomas podem estar presentes mas não são incluídos na definição diagnóstica.

Conforme já mencionado, a divisão da RSC em RSCcPN e RSCsPN é apoiada por achados histológicos e citocinas inflamatórias. ${ }^{6,98}$ Diferenças na resposta ao tratamento e taxas de recorrência também corroboram a divisão em categorias distintas ${ }^{99}$, com a RSC sem pólipos nasais apresentando melhor resposta ao tratamento proposto e menor taxa de recorrência. No entanto, é possível que no futuro seja criada uma categorização guiada por biomarcador, portanto mais precisa. $^{5}$

A anamnese, o exame físico, o exame endoscópico e de imagem apropriado (tomografia computadorizada ou ressonância magnética) são suficientes para o diagnóstico da RSC e sua diferenciação relativa à presença ou não de pólipos nasais. O diagnóstico diferencial de RSC sem pólipos nasais inclui: rinopatia (alérgica, eosinofílica, hormonal, medicamentosa, irritativa, atrófica, idiopática), refluxo gastroesofágico, asma, cefaleias não rinogênicas (migrânea, tensional), dor miofacial, disfunção têmporo-mandibular, infecção dentária crônica, corpo estranho, neoplasia nasossinusal benigna ou maligna e até fístula liquórica nasal. ${ }^{100-105}$

Desde 1997, grupos de especialistas em RSC propuseram critérios diagnósticos diferentes, com combinações variadas dos sintomas e duração dos mesmos. As publicações mais recentes atestam a necessidade de confirmação com a endoscopia nasossinusal e a tomografia computadorizada para se chegar a este diagnóstico. ${ }^{14,16,106,107}$ Apesar da necessidade de se documentarem achados objetivos da inflamação nasossinusal, poucos estudos têm abordado o prazo e a sequência de testes usados para validar um diagnóstico de RSC da melhor forma custo-efetiva. ${ }^{5}$ A discussão da eficiência de custos do diagnóstico da RSC é altamente dependente dos custos diretos específicos do sistema de saúde em questão, com a disponibilidade de profissionais, as modalidades de diagnóstico existentes e regimes terapêuticos para RSC. Os custos indiretos, incluindo a exposição à radiação, tempo de trabalho perdido e possíveis complicações relacionadas com intervenções terapêuticas, são mais difíceis de serem objetivamente mensurados, porém tão importantes quanto os custos diretos. ${ }^{5}$

Há algoritmos publicados com o estabelecimento diagnóstico a partir dos 
sintomas seguido por videoendoscopia nasal. ${ }^{108,109}$ O diagnóstico por imagem, especialmente realizado com tomografia computadorizada de seios paranasais, é recomendado para pacientes sintomáticos com resultados duvidosos ou normais à videoendoscopia nasal. ${ }^{110} \mathrm{O}$ planejamento cirúrgico terapêutico, por outro lado, sempre deve ser acompanhado por exames de imagem, sendo recomendada a tomografia de seios paranasais. A ressonância magnética tem uso limitado para o diagnóstico de RSC, estando indicada para delineamento de mucoceles, sinusite fúngica alérgica, avaliação da integridade da base do crânio ou presença de tumores nasossinusais. ${ }^{5}$

\subsubsection{MANEJO DA RSC}

O manejo da RSC se faz por meio de terapia medicamentosa tópica e oral para controle dos sintomas, além de cirurgia endoscópica nasossinusal para remoção dos pólipos quando presentes e ampla abertura dos seios paranasais que permita melhor aeração e penetração das medicações tópicas. ${ }^{5,111}$

A terapia tópica nasal de manutenção recomendada pelas diretrizes mais recentes $^{4,5}$ consiste em irrigação com solução salina e o uso de corticoesteróides tópicos.

A irrigação pode ser realizada com solução salina isotônica ou hipertônica (com resultados similares na melhora subjetiva dos sintomas) e em alto volume $(>100 \mathrm{ml})$, que apresenta resultados superiores à de baixo volume (spray). ${ }^{5}$ Os efeitos adversos menores incluem ardência nasal, otalgia, cefaleia e náusea e sua incidência é estimada em 5-10\% das irrigações com solução isotônica e em 10-25\% das irrigações com solução hipertônica. ${ }^{112}$ Não foram encontrados efeitos adversos maiores em uma metanálise de 22 ensaios clínicos. ${ }^{112}$ A recomendação estabelecida em consenso de se irrigar as fossas nasais com solução salina a longo prazo se dá a partir dos benefícios clínico-radiológicos apresentados, excelente perfil de segurança e custo relativamente baixo, estimado em US\$ 0,24 por dia. ${ }^{113}$

A terapia tópica com corticosteróides em spray é eficaz em reduzir o escore de sintomas e achados endoscópicos, especialmente em pacientes com RSCcPN. Seu custo diário varia entre US\$ 0.61 e US\$ 4,80. ${ }^{113}$ Existem outras formas de aplicação além do spray, como a irrigação com solução contendo corticosteróide e dispositivos de liberação lenta inseridos cirurgicamente. Entretanto, apresentam 
indicação limitada (melhor indicado em pacientes com polipose extensa em pósoperatório), custos mais elevados se comparados aos sprays e há relativamente menos estudos que avaliam seus resultados. ${ }^{5}$ Como efeitos adversos menores da corticoterapia tópica citam-se epistaxe, ressecamento nasal e cefaleia. A absorção sistêmica nas doses empregadas é mínima, o que não promove supressão da glândula adrenal como inicialmente suspeitado. ${ }^{114,115}$ Também não foram encontradas diferenças na pressão intraocular ou dosagens de cortisol sérico ou urinário nos pacientes com RSC que fazem uso de corticoterapia tópica continuada. ${ }^{5,115}$

As agudizações dos pacientes com RSC devem ser tratadas com antibioticoterapia sistêmica adequada. Os corticosteróides orais são opção de tratamento nos pacientes com RSC, especialmente nos períodos de agudização, tendo maior benefício nos pacientes com RSCcPN. ${ }^{5}$ A corticoterapia oral deve ser usada por curto período de tempo (menos de 2 semanas) na menor dose possível e com frequência única a cada 2 anos. $^{5}$

O objetivo da cirurgia endoscópica funcional e do tratamento clínico de manutenção para os pacientes com RSC é a eliminação ou controle dos sintomas (EVA menor ou igual a 3) de forma a impedir o comprometimento da qualidade de vida de forma significativa nos indivíduos afetados. ${ }^{4}$

\subsection{HALITOSE}

\subsubsection{DADOS GERAIS}

A preocupação com o hálito pela humanidade data de períodos remotos da história. Hipócrates já mencionava que "se a gengiva se torna saudável novamente, o odor ofensivo se esvai". ${ }^{116}$

A questão do mau hálito se mantém atual na sociedade moderna. Na América Latina, ocorreu um aumento de $12 \%$ nas vendas de produtos de higiene e beleza entre 2002 e 2003. Houve aumento significativo no consumo per capita de pasta de dente, escova de dente, enxaguantes bucais e fio dental entre 1992 e 2002, respectivamente em taxas de $38,3 \%, 138,3 \%, 618,8 \%$ e $177,2 \% .{ }^{117}$

Em 1991 foram estabelecidos critérios para pesquisas nesta área durante o primeiro simpósio internacional intitulado Directions in Halitosis Research. ${ }^{118} \mathrm{Em}$ 
1993, foi criado um grupo de estudo e pesquisa em halitose intitulado International Society for Breath Odor Research (ISBOR) e a partir de então, o assunto passou a receber uma abordagem multidisciplinar. No Brasil, em 1998 foi fundada a Associação Brasileira de Estudos e Pesquisas dos Odores da Boca (ABPO) com a finalidade de promover e aprimorar estudos na área da halitose, atualmente denominada Associação Brasileira de Halitose (ABHA). ${ }^{119}$

A halitose causa embaraço social, emocional e psicológico, afetando a autoestima, autoimagem e autoconfiança dos pacientes e provoca, consequentemente, mudança do padrão comportamental e exclusão social. ${ }^{120,121} \mathrm{Na}$ prática clínica, percebe-se que falar sobre mau hálito tem sido algo difícil para o paciente, pois ele raramente relata que o motivo principal de sua consulta seja a preocupação com seu odor bucal. ${ }^{119}$ Observa-se, ainda, que o profissional de saúde também apresenta dificuldade em diagnosticar aqueles que possuem halitose. ${ }^{122}$

\subsubsection{DEFINIÇÃO E TERMINOLOGIA}

Etimologicamente halitose é uma palavra originada do latim, onde halitus significa ar expirado e ose, alteração patológica. Apesar da presença do sufixo ose na palavra halitose, trata-se de um evento clínico e não doença. ${ }^{119}$

A halitose é definida como a percepção de uma alteração na qualidade do odor do fluxo expiratório. Será considerada halitose real ou genuína quando perceptível pelo examinador e pseudo-halitose quando perceptível apenas pelo paciente. ${ }^{7,12}$ Halitofobia é definida como uma preocupação excessiva em presença de pseudo-halitose, quando o paciente se recusa a acreditar na ausência de achados objetivos que atestem a presença de halitose real. ${ }^{7,12}$

Assim, a halitose pode se manifestar como um sinal, halitose clínica (também denominada de genuína ou real); ou como um sintoma, halitose subclínica (pseudohalitose ou imaginária). Ambas se origininam de processos fisiológicos, adaptativos e/ou patológicos e se diferenciam, respectivamente, pela presença ou ausência de odorivetores no fluxo expiratório. Odorivetores são moléculas de baixo peso molecular, lipossolúveis, que se dispersam no ar e sensibilizam o epitélio olfatório. ${ }^{7,8,119,122}$ 


\subsubsection{EPIDEMIOLOGIA E IMPACTO NA QUALIDADE DE VIDA}

A halitose figura como a terceira causa mais frequente de consulta ao dentista em alguns estudos, estando cárie dentária e doenças periodontais como primeira e segunda causas, respectivamente. ${ }^{123}$

Os dados sobre prevalência da halitose são conflitantes na literatura devido principalmente à forma de aferição. Muitos estudos são baseados na estimativa subjetiva pelo próprio paciente, o que é limitado em termos de acurácia e sensibilidade, outros por diagnóstico objetivo, mas com diferentes limiares. ${ }^{12}$ Há estudos que estimam a prevalência de halitose em $30-50 \%$ da população, ${ }^{124,125}$ enquanto outros demonstram uma prevalência menor, de cerca de $15 \% .{ }^{11} \mathrm{Na}$ China, um grande estudo epidemiológico reuniu 2000 participantes entre 15 e 64 anos. Aproximadamente $28 \%$ da população estudada foi diagnosticada com halitose por meio do teste organoléptico (TO), enquanto $20,3 \%$ e $35,4 \%$ dos participantes tinham compostos sulfurados voláteis maiores que 110 partes por bilhão (ppb) e 75 ppb, respectivamente. $^{124}$ No Japão, $28 \%$ dos 2672 indivíduos avaliados tinham CSV maiores que 75 ppb. ${ }^{126}$ Um estudo brasileiro ${ }^{11}$ estimou a prevalência de halitose em $15 \%$ por meio de questionários, sendo maior em homens e em pacientes acima de 20 anos de idade.

\subsubsection{TIPOS DE ODORIVETORES}

Os principais odorivetores são:8,122,127,128

- $\quad$ À base de enxofre - os chamados CSV: sulfetos de hidrogênio $\left(\mathrm{H}_{2} \mathrm{~S}\right)$, as metilmercaptanas $\left(\mathrm{CH}_{3} \mathrm{SH}\right)$ e os dimetilsulfetos $\left[\left(\mathrm{CH}_{3}\right)_{2} \mathrm{~S}\right]$.

- À base dos produtos usuais da putrefação - COV: putrescina, cadaverina, fenóis, cetonas, ácidos graxos de cadeia curta e compostos hidrogenados (amônia, uréia, dimetilamina, trimetilamina).

Dentre estes, o sulfeto de hidrogênio e a metilmercaptana são os odorivetores responsáveis por aproximadamente $90 \%$ do odor bucal. ${ }^{129,130}$

Em relação ao local de formação, os odorivetores podem ser de origem : ${ }^{119}$

\footnotetext{
Bucal

- $\quad$ Sistêmica

- Bucal e sistêmica
} 


\section{- $\quad$ Local (bucal + vias aéreas superiores)}

Cerca de 80 a $90 \%$ dos casos de halitose têm origem bucal. ${ }^{10,12,131}$ In vitro, muitas bactérias presentes na saliva, biofilme dental e biofilme lingual podem produzir $\mathrm{CSV}$, especialmente $\mathrm{CH}_{3} \mathrm{SH}$ e $\mathrm{H}_{2} \mathrm{~S}$, além de ácidos graxos de cadeia curta como ácido butírico, propiônico, ácidos valéricos e cadaverina, o que contribui para a complexa mistura de odorivetores encontrada no ar exalado. ${ }^{131,132}$ In vivo, as mesmas bactérias degradam peptídeos e aminoácidos encontrados na saliva, fluido crevicular gengival, sangue, restos de alimentos retidos entre os dentes e células epiteliais descamadas. ${ }^{129,131,132}$ Quando saliva ou placa subgengival são deixadas para putrefação in vitro, predominam bactérias anaeróbias Gram-negativas que podem ser inibidas pelo metronidazol, um agente antimicrobiano específico para anaeróbios. ${ }^{129,133}$ No biofilme subgengival há espécies de organismos como $F$. Nucleatum, T. Denticola, P. Intermedia, P. Gingivalis, T.forsythia, Eubacterium e outras capazes de produzir grandes quantidades de $\mathrm{CH}_{3} \mathrm{SH}$ e $\mathrm{H}_{2} \mathrm{~S}$ a partir da metionina, cisteína ou proteínas séricas. ${ }^{129,133}$

\subsubsection{CLASSIFICAÇÃO DA HALITOSE}

A halitose pode ser dividida de acordo com o local de origem dos odorivetores e presença ou não de comprometimento patológico. ${ }^{119}$

1. Halitose bucal sem envolvimento patológico: aparelhos ortodônticos, próteses e restaurações mal adaptadas, alterações morfológicas bucais (fissura lingual, hipertrofia de papilas linguais, inserção alta de bridas e freios), estados de pós-operatório;

2. Halitose bucal com envolvimento patológico: doença periodontal, lesões em tecidos moles bucais (líquen plano ou bolhoso, pênfigo, fístulas), cárie, hipovitaminoses (A, C, D);

3. Halitose bucal-sistêmica sem envolvimento patológico: halitose da fome, da manhã, do regime, do estresse, por medicamentos, do alimento de odor carregado, alterações hormonais (menstruação, gravidez);

4. Halitose bucal-sistêmica com envolvimento patológico: refluxo gastroesofágico, dispepsia, divertículo de Zenker, gastroenterites, diarreia, diabetes descompensado, hipo ou hipertireoidismo, estados febris, alterações pancreáticas (pancreatite crônica, obstrução do ducto pancreático ou câncer de pâncreas), 
alcoolismo, entre outros;

5. Halitose sistêmica sem envolvimento patológico: lentidão do trânsito intestinal;

6. Halitose sistêmica com envolvimento patológico: alterações hepáticas (cirrose, insuficiência hepática, neoplasia), renais (insuficiência renal crônica, uremia), pulmonares (abscessos, broncoectasias, empiemas, neoplasias, broncopneumonias), erros inatos do metabolismo, alterações intestinais que levam à lentidão do bolo fecal (divertículos, estenoses, megacólon e obstrução intestinal);

7. Halitose local sem envolvimento patológico: corpos estranhos na via aerodigestiva, criptas amigdalianas com cáseos, desvio septal que favoreça a respiração bucal; ${ }^{121,134}$

8. Halitose local com envolvimento patológico: faringoamigdalites, neoplasias faringo-amigdalianas, doenças das vias aéreas superiores e seios paranasais (adenoidites, rinites e rinossinusites). ${ }^{134}$ Por ser objeto de estudo deste trabalho, o tema será mais profundamente abordado na próxima subseção, Halitose e Rinossinusite Crônica.

\subsubsection{DIAGNÓSTICO}

A halimetria é o exame que irá avaliar a presença ou não de compostos voláteis de odor carregado. Para a realização dos exames de medição do hálito, o paciente deverá ter seguido as orientações pré-halitometria, bem como o operador que for executar esta tarefa também não poderá estar em uso de qualquer tipo de substância odorífera. Assim, evita-se que essências oriundas de perfumes, loções, shampoos e outros interfiram com os sensores eletrônicos dos equipamentos que possam alterar os resultados dos exames, permitindo, desta forma, a padronização de uma metodologia aplicada a todos.

\subsubsection{TESTE ORGANOLÉPTICO}

Realizado pelo olfato do examinador ou por quem ele designar em sua equipe. ${ }^{135}$ Para a realização do teste, o profissional se posiciona a 15 centímetros de distância da cavidade bucal do paciente e solicita para que o mesmo exale o ar apenas pela boca.

Este método é subjetivo, já que depende da capacidade olfativa do avaliador. Esta pode sofrer oscilações periódicas e necessita ser calibrada. ${ }^{136,137}$ É 
recomendado que o examinador adie a avaliação caso tenha algum distúrbio olfatório como rinopatia, gotejamento pós-nasal, resfriado ou rinossinusite. ${ }^{135}$ Outras desvantagens citadas na literatura é que este método pode causar constrangimento ao paciente e/ou examinador bem como favorecer a transmissão de doenças por partículas respiratórias inaladas. ${ }^{138}$

Entretanto, mesmo com as desvantagens citadas, a avaliação organoléptica é considerada padrão-ouro, ${ }^{129}$ visto que é o único método disponível clinicamente para avaliar simultaneamente todos os odorivetores. Os equipamentos portáteis objetivos disponíveis para uso clínico identificam apenas os CSV e não os COV.

A avaliação organoléptica pode ser considerada: ${ }^{135}$

- Qualitativa: sim/não

- Semiquantitativa: ${ }^{139}$

- 1: odor natural ou ausência de odor;

- 2: halitose da intimidade: percepção do odor à distância de $15 \mathrm{~cm}$;

- 3: Halitose do interlocutor: percepção do odor à distância de $50 \mathrm{~cm}$;

- 4: Halitose social: percepção do odor no ambiente.

\subsubsection{HALIMETER ${ }^{\circledR}$ (Interscan Corp, Chatsworth, CA)}

Trata-se de um monitor portátil que quantifica partículas por bilhão de enxofre por meio da ativação de um sensor eletroquímico pelos CSV. Durante essa ativação eletroquímica, os CSV se ionizam e liberam elétrons que sensibilizam o circuito elétrico gerando corrente elétrica diretamente proporcional à concentração do gás ionizado. ${ }^{116,118,136}$

A avaliação com o Halimeter $^{\circledR}$ é realizada por meio da introdução do canudo descartável conectado no aparelho e levado à região posterior da boca (aproximadamente $4 \mathrm{~cm}$ ) para a aferição do CSV bucal. Logo após realiza-se a tomada nasal introduzindo-se o canudo $1 \mathrm{~cm}$ no interior da fossa nasal direita, obstruindo-se a saída do ar da narina contralateral e solicita-se ao paciente exalar o ar vagarosamente. Repete-se este procedimento na outra narina para aferição do CSV de fossa nasal direita e esquerda, respectivamente. ${ }^{136,140}$

Atualmente, o Halimeter ${ }^{\circledR}$ é o equipamento mais utilizado nas pesquisas científicas da halitose. Entretanto, embora este monitor seja portátil, de fácil 
utilização e forneça uma medida objetiva, ele apresenta algumas limitações de uso, pois não identifica os COV, exceção feita aos tióis, e apresenta baixa sensibilidade para as metilmercaptanas. ${ }^{120}$ Os CSV avaliados pelo Halimeter ${ }^{\circledR}$ são responsáveis por $18 \%$ a $41 \%$ da positividade dos testes organolépticos, demonstrando, assim, que outros importantes odorivetores contribuem para a halitose mas não são detectados pelo Halimeter ${ }^{\circledR} .^{129}$ Seu uso é indicado para monitoramento do tratamento da halitose, por permitir medidas consecutivas e quantificar os sulfidretos e dimetilsulfetos, quando estes forem os principais responsáveis pela halitose. ${ }^{129,136,137,140}$

\subsubsection{A IMPORTÂNCIA DA SIALOMETRIA}

Após a halimetria é importante a realização da sialometria, que consiste na avaliação da quantidade e qualidade salivar. É um recurso diagnóstico simples, barato e fundamental, pois a quantidade e viscosidade salivar são fatores que influenciam o processo de halitose. Um fluxo salivar reduzido prejudica a autolimpeza bucal e situações críticas de redução podem causar alterações senso perceptivas gustativas. Uma saliva muito viscosa apresenta grande concentração de glicoproteínas que sofrerão atuação de uma série de enzimas, como por exemplo a alfa-galactosidase, que promove a quebra das cadeias laterais dos carboidratos da glicose (deglicolização). ${ }^{141}$ Consequentemente, há maior crescimento bacteriano no meio salivar, pois as mesmas se utilizam desse carboidrato liberado para crescerem e posteriormente degradarem a saliva, gerando CSV. ${ }^{140,141}$

A viscosidade salivar aumentada poderá também estar sendo acompanhada de maior formação de muco nasal e consequente obstrução das vias aéreas superiores, sendo todos esses fatores contribuintes da halitose. Estas alterações podem estar sinalizando precocemente processos alérgicos e doenças autoimunes. $^{141}$

A sialometria é realizada com o paciente em repouso e sob estímulo salivar em que o mesmo mastiga um dispositivo de silicone durante o tempo de 5 minutos. O paciente é orientado a depositar toda a saliva em um recipiente de forma a se aferir o fluxo salivar em $\mathrm{ml} / \mathrm{min}$ ao fim do procedimento. Os valores sialométricos são então analisados conforme a Tabela $1 .{ }^{142,143}$ 
Tabela 1 - Classificação do fluxo salivar ${ }^{142}$

\begin{tabular}{lccc}
\hline Fluxo salivar em $\mathrm{mL} / \mathrm{min}$ & Muito baixo & Baixo & Normal \\
\hline Em repouso & $<0,1$ & 0,1 a 0,25 & $>0,25$ \\
Sob estímulo mecânico & $<0,7$ & 0,7 a 1,0 & $>1,0$ \\
\hline
\end{tabular}

\subsection{HALITOSE E RSC}

Não existe na literatura atual evidência do exato mecanismo fisiopatológico por meio do qual a RSC possa causar halitose clínica ou subclínica. Nas rinossinusites há inflamação da mucosa nasossinusal e obstrução dos óstios de drenagem, o que acarreta maior retenção e decomposição do muco, além de incremento da microbiota proteolítica. Consequentemente, cogita-se que isso resultará em maior liberação de CSV e outras substâncias voláteis. ${ }^{144}$ Ainda, quando existe obstrução nasal importante na RSC, o paciente se torna respirador bucal, o que leva ao aumento da descamação da mucosa bucal por ressecamento, e hipossalivação, ambos contribuindo para a halitose. ${ }^{145} \mathrm{~A}$ redução do fluxo salivar prejudica a limpeza mecânica e ação antimicrobiana da saliva e resulta em aumento do crescimento bacteriano na cavidade bucal. Quanto maior a microbiota proteolítica, maior a liberação de CSV a partir da ação bacteriana. ${ }^{144}$ 


\section{JUSTIFICATIVA}

Há relato de que 50 a $70 \%$ dos pacientes com RSC podem apresentar queixa de halitose. ${ }^{146} E$ É importante interpretar as publicações de halitose como sintoma de RSC com cautela visto que em alguns estudos esse dado é auto-referido. Ou seja, não confirmado nem pelo teste organoléptico, considerado padrão ouro, nem pela avaliação com monitores portáteis de CSV. Estudiosos não familiares com a complexidade da halitose podem assumir erroneamente a halitose auto-referida como uma medida objetiva de halitose. ${ }^{144} \mathrm{~A}$ halitose subclínica pode responder por 5 a $71 \%$ das queixas de halitose e são explicadas em parte por fatores psicogênicos, além de olfação retronasal ou disfunções sensoriais. ${ }^{7,10}$ Da mesma forma, em publicações relativas à halitose é importante que o dado de RSC seja verificado quanto ao diagnóstico firmado por um profissional de saúde e não auto-referência pelo paciente.

Devido à ausência de publicações sobre a relação entre RSC e halitose, o tema permanece sujeito a inferências e suposições sem comprovação científica. A literatura atualmente disponível carece de informações sobre associação de sinais e sintomas da RSC com a presença e intensidade da halitose, bem como de dados que caracterizem a halitose como um preditor de intervenção clínica diferenciada na RSC ou seguimento destes pacientes.

A elucidação de possível associação entre a RSC e halitose pode ser, portanto, inovadora no manejo e seguimento destes pacientes de forma a devolvêlos o pleno conforto nasossinusal e de hálito a partir da correta identificação e terapêutica empregada. 


\section{OBJETIVOS}

Objetivo geral: Comparar os níveis de CSV oral e nasal de pacientes com e sem RSC.

Objetivos específicos:

- Analisar o odor bucal dos pacientes com e sem RSC por meio do teste organoléptico e medida de CSV oral.

- Avaliar se a prevalência de halitose nos pacientes com RSC é maior que a de pacientes sem RSC. 


\section{METODOLOGIA}

\subsection{DELINEAMENTO}

Trata-se de estudo observacional transversal.

\subsection{POPULAÇÃO}

O estudo foi conduzido em pacientes com RSC atendidos em dois hospitais públicos terciários localizados em Brasília-DF: Hospital Universitário de Brasília e Hospital de Base do Distrito Federal. Ambos os hospitais possuem serviço de Otorrinolaringologia com ambulatório específico de Rinologia. Dessa forma, atendem pacientes com perfis sócio-econômicos e patológicos semelhantes.

Os pacientes do grupo controle eram provenientes dos serviços de otorrinolaringologia supracitados (de outros ambulatórios que não o de Rinologia) ou acompanhantes dos pacientes do grupo caso.

O estudo foi conduzido em conformidade com os princípios estabelecidos na Declaração de Helsinki da Associação Médica Americana e da Resolução 466/12 do Conselho Nacional de Saúde. O projeto foi aprovado pelo Comitê de Ética em Pesquisa da Faculdade de Medicina da Universidade de Brasília (Certificado de Apresentação para Apreciação Ética - CAAE número 40348115.0.0000.5558) (Anexo 1).

O recrutamento se deu de forma consecutiva com início em maio de 2015 e término em março de 2016. Todos os participantes eram informados sobre a pesquisa e, caso concordassem em participar, assinavam um termo de consentimento livre e esclarecido (Apêndice 1).

\subsubsection{CRITÉRIOS DE INCLUSÃO}

Critérios de inclusão para o grupo RSC:

- Indivíduos com idade entre 18 e 70 anos;

- Diagnóstico de RSC firmado no ambulatório de Rinologia a partir dos critérios clínicos e endoscópicos e/ou tomográficos. ${ }^{4,5}$

Critérios de inclusão para o grupo controle: 
- Indivíduos com idade entre 18 e 70 anos;

- Ausência de alterações nasossinusais constatada em consulta médica otorrinolaringológica e exame endoscópico nasossinusal se necessário.

\subsubsection{CRITÉRIOS DE EXCLUSÃO}

Critérios de exclusão para ambos os grupos:

- Presença de doença periodontal ativa;

- Uso de antibiótico nas quatro semanas anteriores à avaliação;

- História de tumor maligno;

- Radiação prévia;

- História conhecida de refluxo gastroesofágico;

- Falência hepática;

- Uso das seguintes medicações durante o período da coleta dos dados: antibióticos, anti-histamínicos e descongestionantes ou qualquer tipo de solução para irrigação nasal.

\subsection{PROCEDIMENTOS CLÍNICOS}

\subsubsection{COLETA DE DADOS DEMOGRÁFICOS E AVALIAÇÃO NASOSSINUSAL}

Os dados foram coletados de forma consecutiva por 2 pesquisadores nos ambulatórios de Otorrinolaringologia do Hospital Universitário de Brasília e Hospital de Base do Distrito Federal nos dias em que os pacientes tinham consulta médica agendada. Foi utilizado um protocolo padrão para a coleta de dados (Apêndice 2) e os dois pesquisadores avaliaram todos os pacientes de forma conjunta.

A pesquisadora número 1 é médica especialista em Otorrinolaringologia e tinha por função:

- Recrutamento e contato telefônico com os pacientes previamente à avaliação para instruções para halimetria;

- Coleta de dados demográficos;

- Confirmação do diagnóstico de RSC por critérios clínicos e endoscópicos e/ou tomográficos dos pacientes do grupo RSC. Realização de videoendoscopia nasal em todos os pacientes do grupo RSC (Figura 1);

- Orientação e coleta de informações relativas à EVA dos sinais e sintomas cardinais da RSC (obstrução, hipo/anosmia, rinorreia, cefaleia/dor facial) e à EVA global da doença nos pacientes com RSC. 
- Orientação para auto-aplicação do questionário SNOT-22 (Anexo 2);

- Consulta otorrinolaringológica, exame físico e/ou endoscópico afim de afastar alterações nasossinusais dos pacientes do grupo controle. Realização de videoendoscopia nasal nos pacientes controle quando necessário;

- Auxílio do pesquisador número 2 na mensuração de CSV oral e nasal.

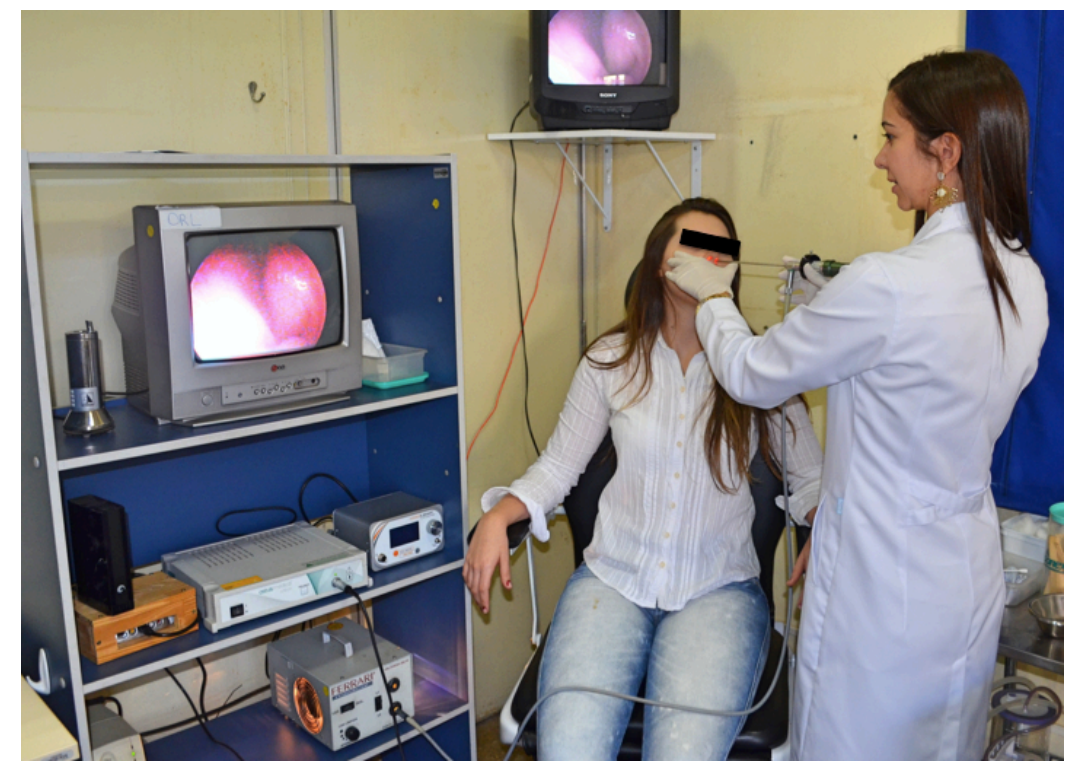

Figura 1. Realização de videoendoscopia nasal

O pesquisador número 2 é cirurgião-dentista treinado e calibrado para avaliação do hálito e era cego em relação ao diagnóstico e exame físico otorrinolaringológico do paciente. Suas funções na coleta de dados eram:

- Halimetria: teste organoléptico, medida dos CSV da cavidade bucal e de fossas nasais (FFNN);

- Sialometria;

- Avaliação periodontal.

- Orientação para auto-aplicação do questionário relativo ao hálito de todos os pacientes do estudo.

\subsubsection{HALIMETRIA}

Em contato telefônico realizado pelo pesquisador número 1 previamente à consulta, os pacientes recebiam as seguintes instruções para realização da halimetria: ${ }^{120}$ 
- Nas 24 horas que antecedem o exame não ingerir alho, cebola, bebida alcóolica ou temperos fortes;

- Nas 12 horas que antecedem o exame não fumar;

- Nas 3 horas que antecedem o exame não tomar café e/ou chá aromatizado;

- No dia do exame não usar cosméticos aromáticos como perfume, desodorante, creme ou loção pós-barba;

- Alimentar-se e realizar a higiene oral habitual 2 horas antes do exame. Não usar fio dental ou soluções para bochechos e/ou gargarejos.

Todos os exames eram realizados entre 9:00 e 11:00 horas ou entre 15:00 e 17:00 horas. O paciente era instruído a permanecer de boca fechada e a respirar somente pelo nariz (quando possível), durante 1 minuto antes de se realizar o teste organoléptico e a avaliação do CSV oral. Para a realização do CSV de FFNN, o paciente era orientado a ocluir as fossas nasais e realizar respiração exclusivamente oral por 1 minuto antes da avaliação de uma fossa nasal e repetir o procedimento antes da avaliação da fossa contralateral.

\subsubsection{TESTE ORGANOLÉPTICO}

O examinador se posicionava a uma distância de $15 \mathrm{~cm}$ (medida com régua de $15 \mathrm{~cm}$ entre o sulco mentoniano do paciente e a base do nariz do examinador) do paciente, que era orientado a exalar lentamente o ar contido na boca à medida que pronunciava a palavra "raaaaaauuuuuuuuussssss" (Figura 2):

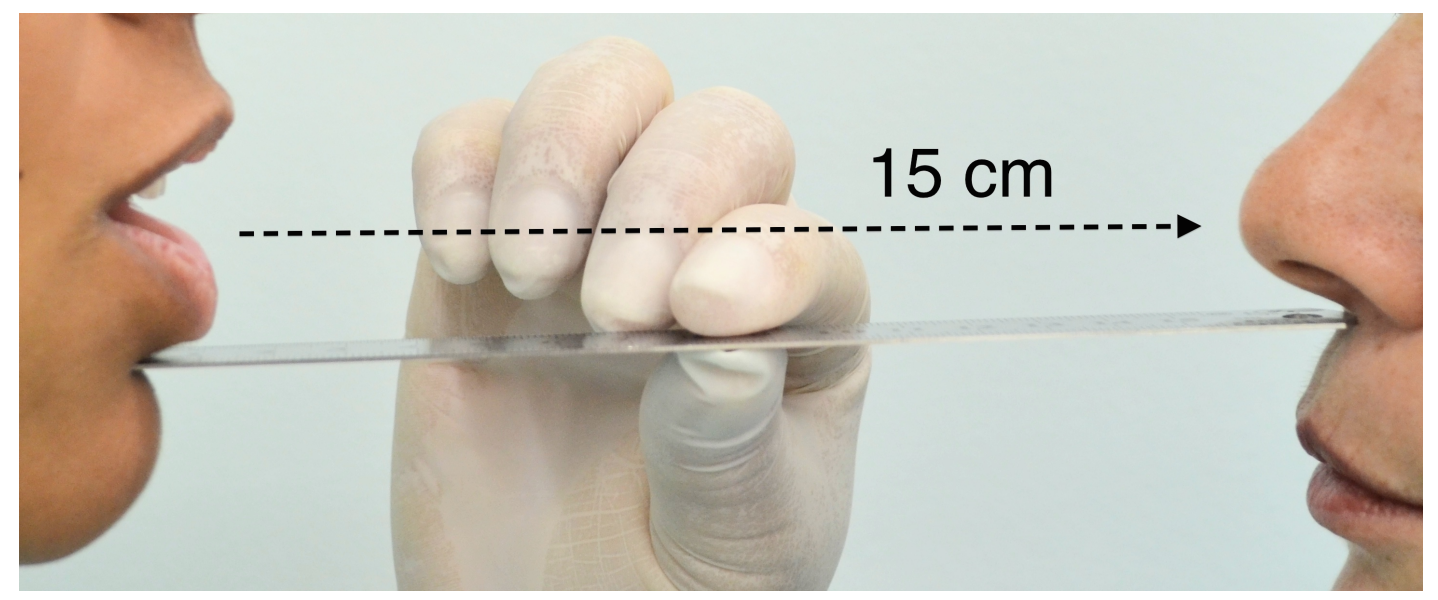

Figura 2. Padronização da distância para avaliação organoléptica 
A pontuação do teste organoléptico era atribuída da seguinte forma: ${ }^{139}$

- 1: Ausência de odor ou odor natural;

- 2: Percepção do odor à distância de $15 \mathrm{~cm}$ (halitose da intimidade);

- 3: Percepção do odor à distância de $50 \mathrm{~cm}$ (halitose do interlocutor);

- 4: Percepção do odor no ambiente (halitose social)

\subsubsection{MEDIDA DOS CSV DA CAVIDADE BUCAL}

Posteriormente à avaliação organoléptica, foi utilizado o Halimeter ${ }^{\circledR}$ para avaliar a concentração de CSV na cavidade bucal e FFNN (Figura 3).

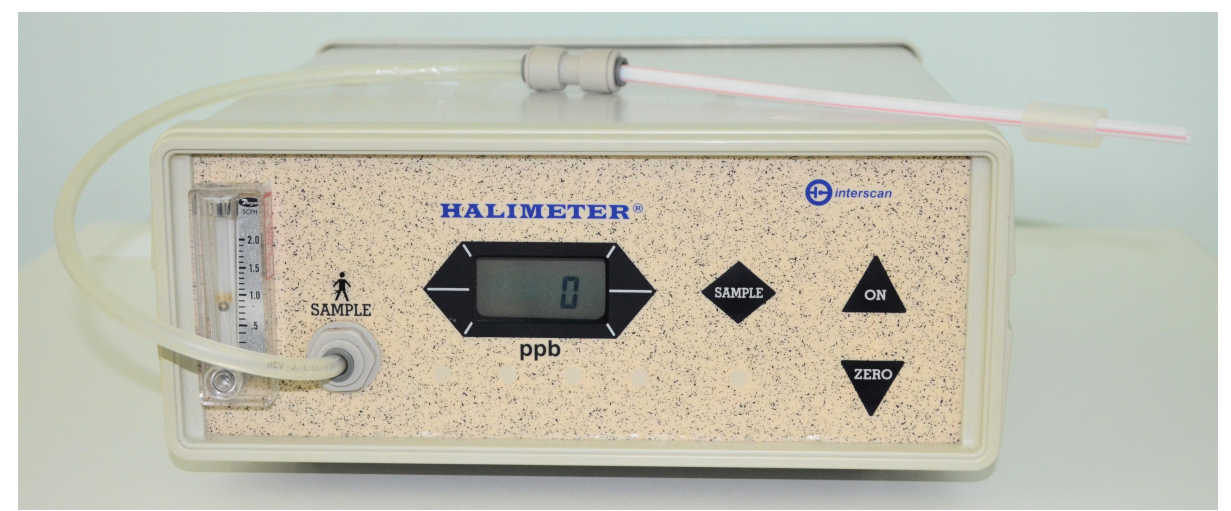

Figura 3. Halimeter ${ }^{\circledR}$

Antes de se iniciar a aferição, o valor de CSV no visor do aparelho era zerado conforme instrução do fabricante. Um canudo descartável conectado à mangueira do sensor do aparelho era introduzido na cavidade bucal do paciente a cerca de $4 \mathrm{~cm}$ dos lábios, de forma que a extremidade do canudo ficasse livre, sem contato com a língua. A vedação do canudo era feita pela preensão pelos lábios do paciente de um dispositivo descartável de silicone (Figura 4). Se o paciente não possuísse fluxo nasal sendo respirador bucal exclusivo, era orientado a realizar a preensão do dispositivo de silicone com os dentes incisivos superiores e inferiores (sem pressionar) e manter os lábios entreabertos de forma que não interrompesse a respiração (Figura 5). 


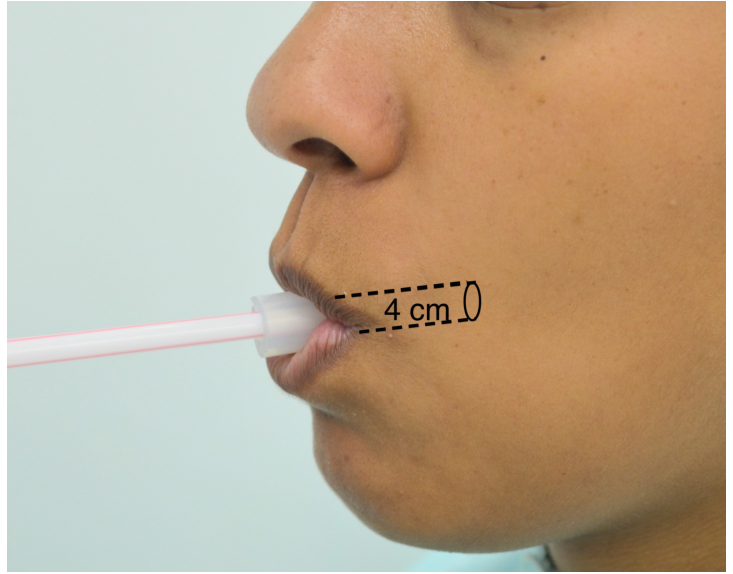

Figura 4. Padronização da localização da extremidade do canudo e vedação labial para aferição dos CSV oral nos pacientes que possuíam fluxo nasal

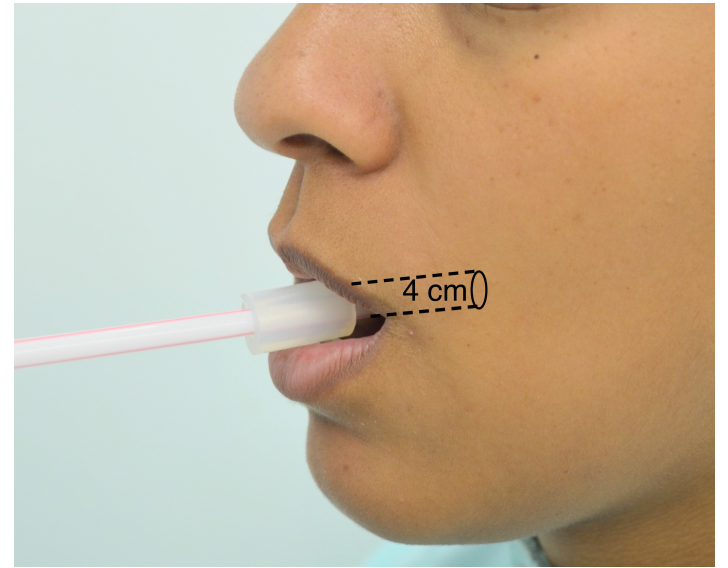

Figura 5. Padronização da localização da extremidade do canudo e ausência de vedação labial para aferição dos CSV oral nos pacientes respiradores bucais

Após o posicionamento, aguardava-se 1 minuto para completar a aferição e o paciente era orientado a permanecer na mesma posição. A concentração de CSV era registrada no visor do aparelho em ppb. O valor considerado como positivo para halitose era superior a $75 \mathrm{ppb}$.

\subsubsection{MEDIDA DOS CSV DAS FOSSAS NASAIS}

Não há na literatura detalhamento de técnica padronizada de aferição de CSV de FFNN. Neste estudo, foi utilizado um canudo descartável com dispositivo de silicone semelhante ao utilizado para aferição dos CSV da cavidade bucal conectado ao sensor do equipamento. O canudo era introduzido $1 \mathrm{~cm}$ em uma fossa nasal, ficando o dispositivo de silicone no vestíbulo. O examinador realizava uma compressão suave do vestíbulo contra o dispositivo de silicone de forma a vedar a fossa nasal sob avaliação, evitando-se, assim, o fluxo nasal ipsilateral à aferição que pudesse dispersar a concentração de CSV (Figura 6). Se o paciente fosse respirador bucal exclusivo a vedação do vestíbulo nasal não era necessária (Figura 7). 


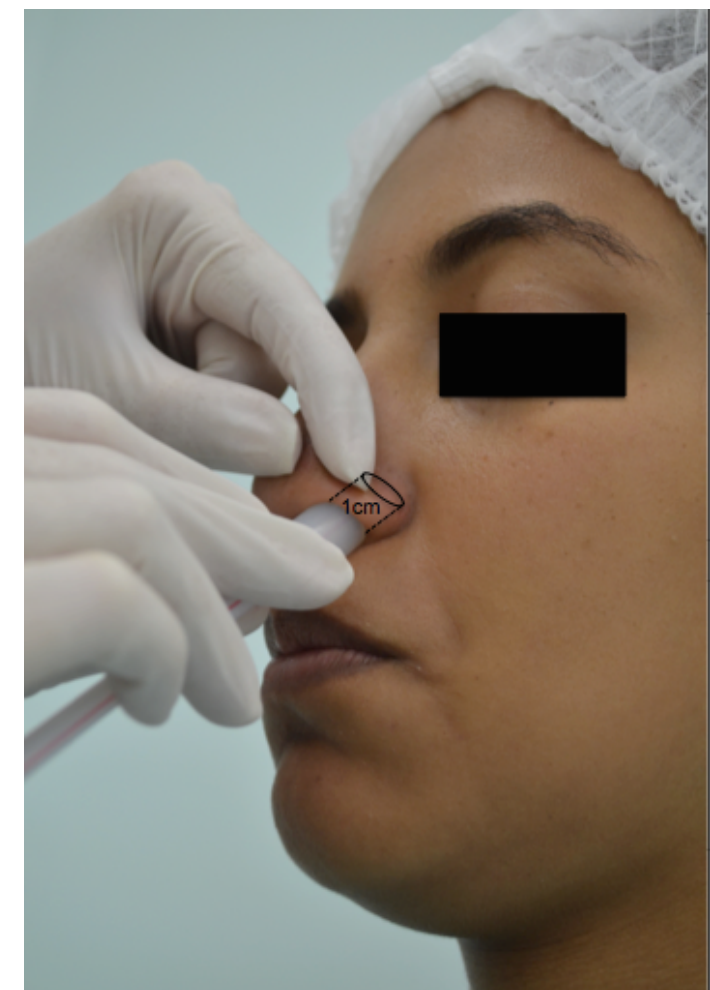

Figura 6. Padronização da localização da extremidade do canudo em fossa nasal e vedação do vestíbulo nasal para aferição do CSV nasal.

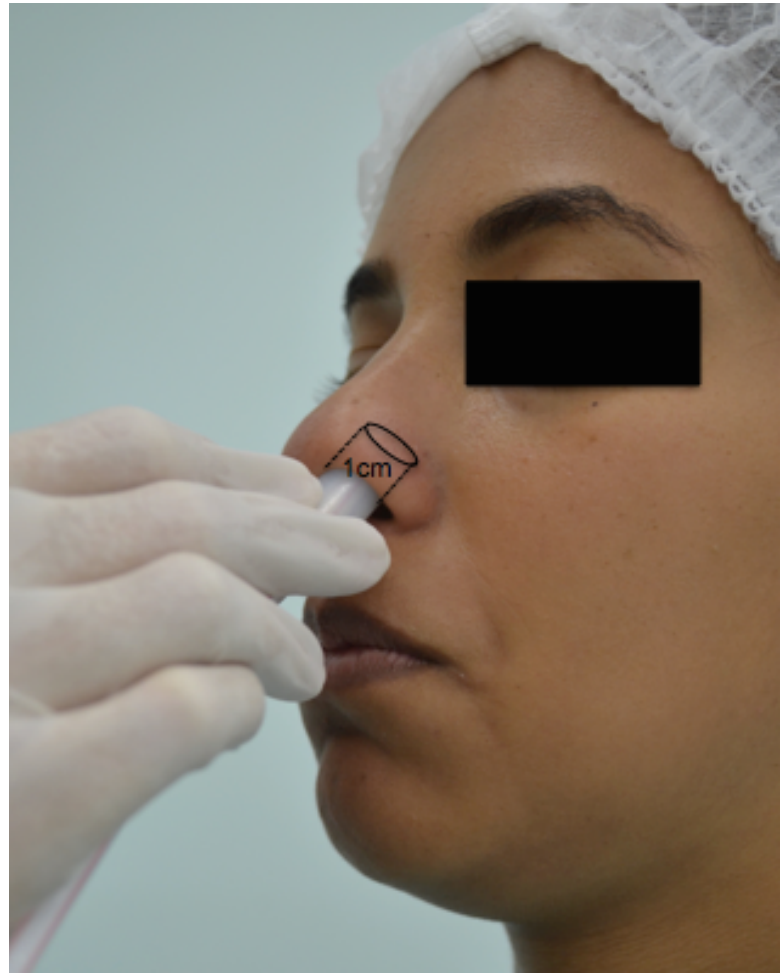

Figura 7. Padronização da localização da extremidade do canudo em fossa nasal sem vedação do vestíbulo nasal nos pacientes respiradores orais para aferição do CSV nasal.

Após o posicionamento do canudo, aguardava-se o tempo de aferição do CSV de cada fossa nasal de 1 minuto e 30 segundos, pois verificou-se em estudo piloto que esta era a média de tempo em que havia estabilização do valor do CSV no visor do aparelho para as fossas nasais. O paciente era orientado a permanecer na mesma posição durante o período, inspirar pela cavidade bucal e expirar pela fossa nasal livre (ou pela própria cavidade bucal se ausência de fluxo nasal).

Terminada a aferição do CSV em uma fossa nasal, o paciente era orientado a ocluir as fossas nasais e realizar respiração oral exclusiva por 1 minuto novamente. O procedimento de aferição era então repetido na fossa nasal contralateral com a mesma técnica descrita.

\subsubsection{SIALOMETRIA}

O tempo para a coleta de saliva foi 5 minutos, tanto para saliva em repouso quanto estimulada. O material era coletado em copos plásticos descartáveis e em seguida aspirado por uma seringa de $10 \mathrm{ml}$, a fim de se quantificar o fluxo de saliva em $\mathrm{mL} /$ minuto. 
Avaliação do fluxo salivar em repouso: paciente de olhos abertos, sentado em cadeira com os pés apoiados no chão e o corpo inclinado para frente. A cabeça ficava inclinada o máximo possível para frente e para baixo, com um copo descartável justaposto ao lábio inferior, de forma que a saliva fluísse gravitacionalmente, sem movimentos de lábios, bochechas e língua (Figura 8).

Avaliação do fluxo salivar estimulado: O paciente se colocava na mesma posição anterior. A estimulação se dava por um dispositivo de silicone de $1 \mathrm{~cm}$ de comprimento que era colocado dentro da boca do paciente para que ele mastigasse, envolto por fio dental que o mesmo era orientado a segurar durante todo o tempo (Figura 9). O paciente era orientado a depositar toda a saliva produzida no copo descartável.

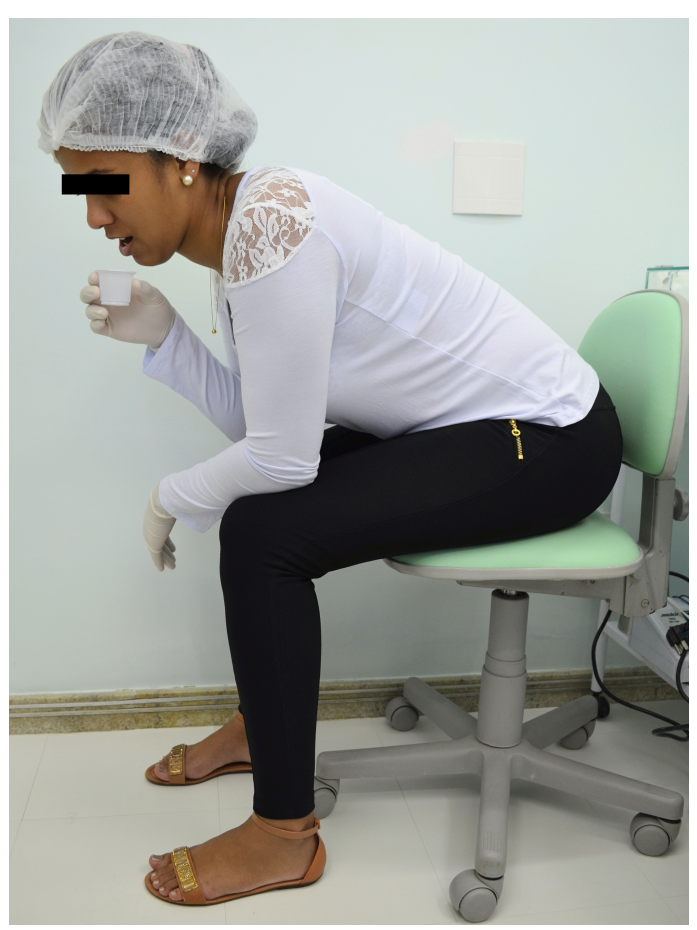

Figura 8. Posição do paciente para coleta do fluxo salivar em repouso.

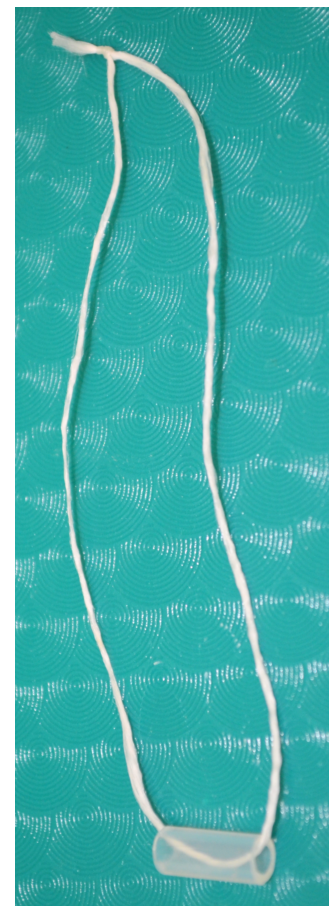

Figura 9. Dispositivo de silicone preso a fio dental utilizado para estímulo de fluxo salivar.

\subsubsection{AVALIAÇÃO PERIODONTAL}

Após a avaliação clínica, halimetria e sialometria, o paciente era submetido a avaliação periodontal com instrumental apropriado. A análise da doença periodontal era feita por meio dos seguintes parâmetros clínicos: profundidade de sondagem, índice de placa e índice de sangramento gengival. ${ }^{147} \mathrm{~A}$ avaliação era realizada por 
meio de sondagem circunferencial em seis sítios de todos os dentes presentes (vestibular, mésio-vestibular, disto-vestibular, lingual, mésio-lingual e disto-lingual) com o auxílio da sonda periodontal Michigan. Assim, para determinação do diagnóstico, foram considerados como tendo doença periodontal pacientes com profundidade de sondagem $>3$ milímetros e sangramento à sondagem em pelo menos dois sítios dentários. Os materiais necessários para esse exame foram: espelho bucal, sonda exploradora, pinça clínica, sonda periodontal milimetrada Michigan e gaze. Caso o paciente fosse portador de doença periodontal ativa no momento da coleta, era excluído do estudo.

\subsubsection{ENCAMINHAMENTO DOS PACIENTES}

A coleta de dados para o estudo em nada interferiu no seguimento dos pacientes nos ambulatórios de Otorrinolaringologia dos serviços referidos.

Diante do diagnóstico de halitose de um paciente do grupo caso ou controle, eram oferecidas informações sobre a halitose e encaminhamento ao serviço de Odontologia do Hospital Universitário de Brasília para investigação e seguimento.

\subsection{ESTATÍSTICA}

\subsubsection{CÁLCULO AMOSTRAL}

O cálculo amostral foi realizado com o programa $G^{*}$ Power $3^{148}$ e resultou numa amostra de 26 participantes em cada grupo (RSC e controle), totalizando 52 pacientes no estudo. Aplicou-se teste-t para grupos independentes, considerando-se hipótese bicaudal, com poder estatístico de $80 \%$, nível de significância de $5 \%$ e magnitude de efeito de 0,8 .

\subsubsection{ANÁLISE DE DADOS}

Os dados foram analisados por meio do programa estatístico SPSS versão 23.0 (SPSS Inc, Chicago, IL, USA), considerando-se o nível de significância de 5\% para testes bi-caudais.

Para as variáveis contínuas foi utilizado o teste $t$ de Student para amostras independentes. As variáveis contínuas que não apresentaram distribuição normal (CSV oral e CSV de FN direita e esquerda) receberam transformação logarítmica na 
base 10 e para interpretação dos resultados foi usado como antilog a média geométrica dos valores. Para as variáveis categóricas foi utilizado o teste quiquadrado. Nenhuma variável apresentou dado omisso. Assim, não foram necessários métodos para imputação de dados. 


\section{RESULTADOS}

Os pacientes foram divididos em grupo controle e grupo RSC conforme critérios listados anteriormente. No grupo RSC, eram subdivididos ainda em RSCcPN ou RSCsPN conforme a existência de pólipos nas fossas nasais para análises separadas. Entretanto, em virtude do reduzido número de pacientes do grupo RSCsPN ( $n=4)$, foi optado por realizar as análises englobando ambos os subgrupos como grupo RSC versus controle.

Os grupos eram homogêneos quanto à distribuição de gêneros, raça e estado civil. Em ambos os grupos a raça de maior prevalência foi a parda (85\% do grupo RSC e $73 \%$ do grupo controle). No grupo RSC a maioria dos pacientes se declarou casado ou pertencente a uma união estável (62\%), enquanto no grupo controle a maioria se declarou solteiro (54\%), sem diferença estatisticamente significante.

Verificou-se que a diferença das médias de idade (45,5 no grupo RSC versus 37,5 no grupo controle), bem como dos anos de escolaridade entre os grupos $(9,7$ no grupo RSC versus 14,5 no grupo controle) foram estatisticamente significativas. A prevalência de comorbidades foi maior no grupo RSC, com destaque para asma (58\%), sensibilidade ao AAS e hipertensão arterial sistêmica (31\% cada) e dislipidemia (19\%). Deviado ao reduzido $\mathrm{n}$ do grupo controle não foi realizada análise estatística.

Outras características demográficas e os antecedentes clínicos são listados na Tabela 2. 
Tabela 2 - Características demográficas e clínicas

\begin{tabular}{|c|c|c|c|}
\hline & \multicolumn{2}{|c|}{ Grupos } & \multirow{3}{*}{ p-valor } \\
\hline & RSC & Controle & \\
\hline & $\mathrm{n}=26$ & $\mathrm{n}=26$ & \\
\hline Gênero masculino (\%) & $11(42)$ & $10(39)$ & 0,777 \\
\hline Idade em anos (média \pm DP) & $45,5 \pm 13,0$ & $37,5 \pm 13,6$ & 0,037 * \\
\hline Anos de estudo (média $\pm \mathrm{DP}$ ) & $9,7 \pm 3,0$ & $14,5 \pm 4,5$ & $<0,001$ * \\
\hline \multicolumn{3}{|l|}{ Raça $(\%)$} & 0.376 \\
\hline Branca & $0(0)$ & $1(4)$ & \\
\hline Negra & $4(15)$ & $5(19)$ & \\
\hline Parda & $22(85)$ & $19(73)$ & \\
\hline Amarela & $0(0)$ & $1(4)$ & \\
\hline \multicolumn{3}{|l|}{ Estado civil (\%) } & 0.062 \\
\hline Solteiro & $6(23)$ & $14(54)$ & \\
\hline Casado / União estável & $16(62)$ & $11(42)$ & \\
\hline Separado / Divorciado & $2(8)$ & $1(4)$ & \\
\hline Viúvo & $2(8)$ & $0(0)$ & \\
\hline \multicolumn{3}{|l|}{ Antecedentes (n, \%) } & - \\
\hline Alergia medicamentosa & $6(23)$ & $0(0)$ & \\
\hline Asma & $15(58)$ & $0(0)$ & \\
\hline Sensibilidade ao AAS & $8(31)$ & $0(0)$ & \\
\hline Hipertensão arterial sistêmica & $8(31)$ & $2(8)$ & \\
\hline Diabetes Mellitus & $3(12)$ & $0(0)$ & \\
\hline Dislipidemia & $5(19)$ & $0(0)$ & \\
\hline Tabagismo & $1(4)$ & $0(0)$ & \\
\hline Cirurgias nasais prévias & $4(15)$ & $3(12)$ & \\
\hline História familiar de asma ou RSC & $4(15)$ & $0(0)$ & \\
\hline \multicolumn{4}{|l|}{ AAS: ácido acetilsalicílico } \\
\hline \multicolumn{4}{|l|}{ DP: desvio-padrão } \\
\hline \multicolumn{4}{|l|}{ n: número absoluto de pacientes } \\
\hline *: significância estatística $(p<0,05)$ & & & \\
\hline
\end{tabular}

Dentre os pacientes com RSC, a pontuação média do questionário SNOT-22 foi 66,4. A média da EVA de cada sinal/sintoma cardinal da RSC em ordem decrescente foi hipo/anosmia $(9,3)$, obstrução nasal $(8,5)$, rinorreia $(7,4)$ e dor facial/cefaleia (5,0). $\mathrm{Na}$ análise da EVA global da doença, $89 \%$ dos pacientes atribuíram escore grave. A prevalência de obstrução nasal completa entre os pacientes com RSC, configurando respiração oral exclusiva, foi $30,7 \%$. As informações clínicas relevantes dos pacientes com RSC são listadas na Tabela 3. 
Tabela 3 - Informações Clínicas sobre os Pacientes com RSC ( $n=26)$

\begin{tabular}{|c|c|}
\hline & Valor \\
\hline SNOT 22 (Média \pm DP) & $66,4 \pm 21,9$ \\
\hline \multicolumn{2}{|l|}{ Sintomas (Média EVA \pm DP ) } \\
\hline Obstrução nasal & $8,5 \pm 1,7$ \\
\hline Rinorreia & $7,4 \pm 2,7$ \\
\hline Dor facial / Cefaleia & $5,0 \pm 3,7$ \\
\hline Hipo / anosmia & $9,3 \pm 1,6$ \\
\hline EVA global da doença (Média \pm DP) & $8,6 \pm 1,8$ \\
\hline Leve: EVA 0 a 3,0 (\%) & $0(0)$ \\
\hline Moderada: EVA 3,1 a 7,0 (\%) & $3(12)$ \\
\hline Grave: EVA 7,1 a $10(\%)$ & $23(89)$ \\
\hline \multicolumn{2}{|l|}{ Achados na VEN (\%) } \\
\hline Pólipo no meato médio & $22(85)$ \\
\hline Edema no meato médio & $16(62)$ \\
\hline Secreção purulenta em fossas nasais & $4(15)$ \\
\hline Desvio septal & $19(73)$ \\
\hline Respiração oral exclusiva (\%) & $8(31)$ \\
\hline \multicolumn{2}{|l|}{ DP: Desvio-padrão } \\
\hline \multicolumn{2}{|l|}{ EVA: Escala Visual Analógica } \\
\hline \multicolumn{2}{|l|}{ n: número absoluto de pacientes } \\
\hline \multicolumn{2}{|l|}{ RSC: Rinossinusite Crônica } \\
\hline \multicolumn{2}{|l|}{ SNOT 22: Sino Nasal Outcome Test } \\
\hline VEN: Videoendoscopia nasal & \\
\hline
\end{tabular}

A prevalência de halitose ao teste organoléptico foi significativamente maior no grupo RSC (31\%) quando comparado ao grupo controle $(8 \%)(p=0,035)$, bem como quando associada a positividade do teste organoléptico à positividade do Halimeter $®$ (CSV oral > 75 ppb) (35\% no grupo RSC versus $19 \%$ no grupo controle) porém sem significância estatística. Em relação ao CSV de FFNN, a média do CSV de fossa nasal direita no grupo RSC $(5,2)$ foi significativamente menor do que o grupo controle $(10,6) \quad(p=0,036)$. A média do CSV de fossa nasal esquerda também foi menor no grupo RSC $(7,9)$ quando comparada ao grupo controle $(11,6)$, porém sem significância estatística.

Não houve diferença estatisticamente significante entre as médias do fluxo salivar em repouso e estimulado entre os grupos. A análise de halimetria e sialometria entre os grupos está listadas na Tabela 4. 
Tabela 4 - Comparação da halimetria e sialometria entre os grupos

\begin{tabular}{|c|c|c|c|}
\hline & \multicolumn{2}{|c|}{ Grupos } & \multirow{3}{*}{ p-valor } \\
\hline & RSC & Controle & \\
\hline & $\mathrm{n}=26$ & $\mathrm{n}=26$ & \\
\hline Teste organoléptico $\geq 2(\%)$ & $8(31)$ & $2(8)$ & 0,035 * \\
\hline \multirow{2}{*}{$\begin{array}{l}\text { CSV oral }>75 \mathrm{ppb}(\%) \\
\text { Halitose (TO } \geq 2 \text { elou CSV oral }>75 \mathrm{ppb}) \\
(\%)\end{array}$} & $3(12)$ & $5(19)$ & 0,440 \\
\hline & $9(35)$ & $5(19)$ & 0,211 \\
\hline \multicolumn{4}{|l|}{ Média ( \pm DP) do CSV das FFNN em ppb } \\
\hline Esquerda & $7,9 \pm 2,8$ & $11,6 \pm 2,8$ & 0,195 \\
\hline Direita & $5,2 \pm 3,7$ & $10,6 \pm 2,9$ & 0,036 * \\
\hline \multicolumn{4}{|l|}{ Fluxo salivar em $\mathrm{mL} / \mathrm{min}$ (Média $\pm \mathrm{DP}$ ) } \\
\hline Repouso & $0,5 \pm 0,2$ & $0,5 \pm 0,3$ & 0,484 \\
\hline Estimulado & $1,0 \pm 0,4$ & $0,9 \pm 0,3$ & 0,670 \\
\hline \multicolumn{4}{|l|}{ *: p estatisticamente significante $(<0.05)$} \\
\hline \multicolumn{4}{|l|}{ CSV: Compostos sulfurados voláteis } \\
\hline \multicolumn{4}{|l|}{ DP: Desvio-padrão } \\
\hline \multicolumn{4}{|l|}{ FFNN: fossas nasais } \\
\hline \multicolumn{4}{|l|}{$\mathrm{mL} / \mathrm{min}$ : mililitros por minuto } \\
\hline \multicolumn{4}{|l|}{$\mathrm{n}$ : número absoluto de pacientes } \\
\hline TO: Teste organoléptico & & & \\
\hline
\end{tabular}

Todos os pacientes responderam seis perguntas do tipo sim/não relativas ao hálito. Conforme evidencia a Tabela 5, 19\% dos pacientes com RSC sentiam o hálito alterado ao momento do exame e $15 \%$ tinham halitose confirmada por terceiros. Entre os pacientes do grupo RSC, 31\% responderam positivamente a pelo menos uma pergunta relativa ao hálito, enquanto que $12 \%$ dos pacientes do grupo controle o fizeram. A prevalência de demais respostas afirmativas está listada na Tabela 5.

Tabela 5 - Respostas afirmativas às perguntas sobre o hálito

\begin{tabular}{lccr} 
& \multicolumn{2}{c}{ Grupos } & \\
\cline { 2 - 3 } & $\mathrm{RSC}$ & $\begin{array}{c}\text { Controle } \\
\mathrm{n}=26\end{array}$ & p-valor \\
\hline \hline 1. Sente o hálito alterado (\%) & $4(15)$ & $1(4)$ & 0,145 \\
2. Halitose confirmada por terceiros (\%) & $4(15)$ & $1(4)$ & 0,145 \\
3. Neste momento sente seu hálito alterado (\%) & $5(19)$ & $1(4)$ & 0,071 \\
4. Já procurou outros profissionais com esta queixa (\%) & $0(0)$ & $0(0)$ & - \\
5. Este problema alterou seu comportamento (\%) & $1(4)$ & $0(0)$ & - \\
6. Acha que as pessoas se afastam enquanto você & $0(0)$ & $0(0)$ & \\
$\quad$ conversa com elas (\%) & $8(31)$ & $3(12)$ & \\
\hline Pelo menos uma das anteriores & &
\end{tabular}

$\mathrm{n}$ : número absoluto de pacientes 


\section{DISCUSSÃO}

O presente estudo foi pioneiro no estabelecimento de relação entre RSC e halitose a partir do teste organoléptico e na descrição dos níveis de CSV bucal e nasal de pacientes com RSC. No manejo dos pacientes com RSC, os profissionais de saúde devem estar atentos também à halimetria para diagnosticar possível halitose mesmo na ausência de queixa ativa desta condição.

Os pacientes do grupo RSC foram inicialmente subdivididos em dois grupos: RSCcPN ( $n=22$ ) e RSCsPN ( $n=4)$ baseado na apresentação fenotípica da doença que portavam. Em virtude de o grupo RSCsPN ter pequena quantidade de pacientes, para efeitos de análise estatística ambos os subgrupos foram analisados em conjunto na comparação com o grupo controle e foram abordados unicamente como grupo RSC neste trabalho. Apesar de existirem duas apresentações fenotípicas da doença de acordo com a via inflamatória de maior atuação, a sintomatologia é semelhante e a associação com halitose tem a mesma base fisiopatogênica, justificando, portanto, a análise em conjunto.

Os grupos RSC e controle tinham o mesmo número de pacientes e eram homogêneos quanto à distribuição de gênero, raça e estado civil. O grupo controle apresentou média de idade oito anos menor que a média do grupo RSC e esta diferença foi estatisticamente significante. Há autores que recomendam atenção à avaliação de halitose em pacientes acima de 85 anos em virtude de maior prevalência de hiposalivação, uso de medicações, doenças sistêmicas e qualidade da higiene dental ${ }^{12,149,150}$ Não há, entretanto, publicações sobre prevalência nesta faixa etária específica comparando com adultos jovens ou crianças. Neste estudo, ambos os grupos se tratavam de adultos jovens e a diferença de oito anos nas médias de idade, apesar de possuir significância estatística, carece de significância clínica. A média de anos de estudo do grupo controle (14,5 anos) foi significativamente maior que a do grupo RSC ( 9,7 anos). Este achado, diferente da média de idade isoladamente, pode refletir em maior conhecimento das causas de halitose, maior busca por atendimento de saúde ou melhores práticas de higiene bucal, o que não foi investigado no estudo.

Os antecedentes clínicos eram auto-referidos pelo paciente, não sendo confirmados por testes específicos por não se tratarem do objeto de estudo. $\mathrm{O}$ grupo 
RSC apresentou prevalência de alergia medicamentosa, asma e sensibilidade ao AAS respectivamente de 23\%,58\% e 31\%. Devido à inexistência destas condições no grupo controle não foi realizada análise estatística. A RSC, especialmente a RSCcPN, é uma doença de caráter inflamatório que está relacionada a outras condições inflamatórias como as supracitadas, o que justifica a maior prevalência neste grupo. Entre os pacientes com RSC, dos oito portadores de sensibilidade ao AAS, seis eram também asmáticos. Há uma entidade clínica denominada DREA (antiga tríade de Samter) atualmente definida pela tétrade asma, polipose nasal, sinusite crônica hipertófica eosinofílica e sensibilidade a qualquer medicação inibidora da enzima ciclo-oxigenase 1 (COX-1) (sabidamente AAS e outras drogas anti-inflamatórias não-esteroidais). ${ }^{151}$ Os pacientes portadores de DREA apresentam polipose nasal mais intensa e de mais difícil controle, com exacerbações frequentes e recidiva após tratamento cirúrgico. ${ }^{49}$ É possível que os seis pacientes que relataram conjuntamente asma e sensibilidade ao AAS sejam portadores de DREA, porém não se pode afirmar com segurança já que não realizaram os exames diagnósticos neste estudo (espirometria e teste de provocação com AAS). Quatro pacientes do grupo RSC relataram ainda história familiar de asma ou RSC.

Foram analisadas as características clínicas dos pacientes com RSC. O SNOT-22 é um questionário amplamente utilizado para avaliação da percepção pelo paciente do prejuízo à sua qualidade de vida que a doença nasossinusal proporciona e está validado para a língua portuguesa. ${ }^{32}$ Trata-se de 22 situações relacionadas aos sintomas nasossinusais às quais o paciente atribui uma nota de intensidade 0 a 5 que será contabilizada para a pontuação final. Dessa forma, a pontuação pode variar entre 0 a 110. A média da pontuação do SNOT-22 no grupo RSC foi 66,4 .

Para complementar a avaliação de intensidade dos sintomas da RSC e prejuízo à qualidade de vida percebido pelo paciente foram avaliadas as pontuações na EVA de cada sintoma cardinal da RSC, sendo o distúrbio da olfação (hipo/anosmia) o de maior gravidade na avaliação dos pacientes (média 9,3), seguido em ordem decrescente por obstrução nasal, rinorreia e dor facial/cefaleia (médias 8,5; 7,4 e 5,0, respectivamente). Foi avaliada ainda a pontuação pela EVA provocada pela doença globalmente, ou seja, com a combinação de todos os sinais e sintomas apresentados, sendo a média da pontuação 8,6. Observa-se que a média da EVA global é cerca de $20 \%$ maior do que a esperada a partir da média de 
pontuação do SNOT-22 (66,4 equivale a cerca de $60 \%$ da máxima pontuação possível, 110), demonstrando diferenças quanto à atribuição de intensidade pelo paciente em escalas visuais e textuais.

Ainda, pode-se classificar a pontuação da EVA global em três categorias de intensidade da doença segundo o $\mathrm{EPOS}^{4}$ em leve (EVA 0 a 3.0), moderada (EVA 3,1 a 7,0) e grave (EVA 7,1 a 10). Nenhum paciente apresentou EVA de intensidade leve e $89 \%$ apresentaram intensidade grave segundo a EVA global. Este dado, somado às pontuações do SNOT, demonstra que o grupo estudado de RSC apresentava sintomas intensos com grande prejuízo à sua qualidade de vida.

Os pacientes com RSC apresentam agudizações eventuais da doença, quando possuem secreção purulenta em fossas nasais. Neste estudo o critério de agudização foi definido como presença de secreção purulenta à VEN no momento da avaliação. A agudização não apresentou relação com halitose. Entre os quatro pacientes com RSC que apresentavam agudização da infecção, nenhum era portador de halitose pelos critérios do TO ou CSV (dados não mostrados).

Para análise da halitometria foram considerados dois testes: a avaliação organoléptica e a medida de CSV pelo Halimeter ${ }^{\circledR}$. O teste organoléptico no presente estudo foi classificado em quatro níveis ordinais (1 a 4 ) significando respectivamente odor natural, halitose da intimidade, halitose do interlocutor e halitose social. Os pacientes com pontuação 2 ou superior no teste eram classificados como positivo para halitose (critério TO). A prevalência de halitose ao TO foi significativamente maior no grupo RSC (31\%) quando comparado ao grupo controle $(8 \%)$. Entre os oito pacientes do grupo RSC positivos para halitose pelo teste organoléptico, seis apresentavam halitose da intimidade, dois halitose do interlocutor e nenhum apresentou halitose social.

Não há consenso na literatura quanto ao ponto de corte do CSV oral aferido pelo Halimeter ${ }^{\circledR}$ para ser considerado dentro da normalidade. Para o presente estudo foi adotado o valor de CSV oral até 75ppb como parâmetro de normalidade seguindo estudos semelhantes de prevalência (critério CSV oral). ${ }^{16,124,126,152}$ Assim, $12 \%$ dos pacientes do grupo RSC e 19\% dos pacientes do grupo controle apresentaram CSV oral $>75 \mathrm{ppb}$, sem diferença estatisticamente significativa.

Assumindo que o teste organoléptico e o Halimeter ${ }^{\circledR}$ fornecem informações complementares para o diganóstico de halitose, verificou-se a prevalência de halitose nos grupos a partir da combinação das avaliações. Assim, definindo critério 
de halitose presente como positividade do TO (pontuação $\geq 2$ ) e/ou CSV oral $>75$ ppb pelo Halimeter ${ }^{\circledR}, 35 \%$ dos pacientes com RSC apresentavam halitose comparados com $19 \%$ dos pacientes do grupo controle. Esta diferença não foi estatisticamente significante. Entre os nove pacientes com RSC portadores de halitose, quatro evidenciaram alguma preocupação com o hálito respondendo afirmativamente a pelo menos uma das perguntas do questionário sobre o hálito, enquanto que entre os cinco pacientes do grupo controle portadores de halitose, nenhum o fez. Sabe-se do constrangimento social e embaraço que a presença de halitose pode provocar no paciente. Em virtude da alta prevalência de hipo/anosmia nos pacientes com RSC por comprometimento mecânico ou inflamatório do epitélio olfatório, os pacientes que demonstraram alguma preocupação com o hálito podem ter sido alertados por alguma pessoa de seu convívio social.

Hipotetizou-se que uma maior concentração de CSV oral poderia estar relacionada a maior prejuízo à qualidade de vida ao paciente portador de RSC e halitose. Não houve, entretanto, correlação estatisticamente significante entre a concentração de CSV oral e a pontuação do SNOT-22.

Não há na literatura descrição de protocolos ou parâmetros de normalidade para a concentração de CSV das FFNN. No presente estudo, as médias do CSV das FFNN foram paradoxalmente maiores no grupo controle quando comparados aos pacientes com RSC, verificando-se que a diferença entre os grupos foi estatisticamente significante nas FFNN direitas (10,6 versus 5,2$)$, mas não para as FFNN esquerdas (11,6 versus 7,9). Sendo a RSC uma doença que acomete difusamente a mucosa nasossinusal e não apenas um lado da cavidade nasal e considerando que as FFNN se comunicam entre si por meio da rinofaringe, não se esperava diferença significativa na concentração de CSV entre as FFNN.

Hipotetizou-se que pacientes com obstrução nasal completa devido à RSC e respiração oral exclusiva poderiam ter maiores níveis de CSV em FFNN ou cavidade bucal devido à deposição de muco, maior gotejamento pós-nasal e proteólise, entretanto isto não se confirmou neste estudo. Entre os oito pacientes com RSC com respiração bucal exclusiva, três eram portadores de halitose segundo critérios de TO e nenhum apresentou CSV bucal $>75 \mathrm{ppb}$.

Sabe-se que a saliva constitui primeira linha de defesa da orofaringe e apresenta funções relacionadas à integridade bucal e sistêmica, como reparação tecidual, neutralização de $\mathrm{pH}$ ácido, auxílio na digestão e ação antimicrobiana. ${ }^{142} \mathrm{~A}$ 
hiposalivação, definida como uma redução do fluxo salivar, está associada à halitose e afeta cerca de $20 \%$ da população de forma dinâmica. O valor de fluxo salivar considerado dentro dos parâmetros de normalidade em repouso é $>0,25 \mathrm{~mL} / \mathrm{min}$ e sob estímulo é $>1,0 \mathrm{~mL} / \mathrm{min} .{ }^{142}$ Quanto à sialometria, os pacientes de ambos os grupos apresentaram fluxo salivar médio em repouso e estimulado dentro dos parâmetros de normalidade, sem diferença estatisticamente significante. $\mathrm{Na}$ análise individualizada dos grupos, verificou-se que doze pacientes com RSC (46\%) apresentavam algum grau de hiposalivação e, dentre estes, quatro eram positivos para halitose pela combinação dos critérios de TO e/ou CSV oral (dados não mostrados). No grupo controle, 13 pacientes (50\%) apresentavam algum grau de hiposalivação e, entre estes, apenas um paciente apresentava halitose por ambos os critérios (apresentou TO $=2$ e CSV oral no valor de $332 \mathrm{ppb}$ ).

A doença periodontal é uma infecção microbiana crônica caracterizada pela inflamação persistente, ruptura do tecido conjuntivo e destruição do osso alveolar. Entre os principais fatores etiológicos estão a presença de bactérias periodontopatogênicas, a ausência das chamadas bactérias benéficas e a suscetibilidade do hospedeiro. ${ }^{153,154}$ Há evidências que sugerem que a doença periodontal aumenta a intensidade do mau odor bucal e a produção de CSV ${ }^{126,153,155}$ e é apontada como uma das etiologias da halitose. Durante a coleta de dados, cinco pacientes foram excluídos devido à presença de doença periodontal no momento do exame (dados não mostrados). Destes, dois seriam do grupo RSC e três do grupo controle. Entre estes cinco pacientes, quatro apresentaram halitose segundo critério adotado no estudo (teste oganoléptico $\geq 2$ e/ou CSV oral $>75 \mathrm{ppb}$ ). Dessa forma, confirma-se que a exclusão de doença periodontal no desenho do estudo permitiu a análise das amostras sem fator confundidor.

Entre as principais limitações do presente estudo, citam-se a não homogeneidade da amostra e a impossibilidade de se comparar os subgrupos RSCcPN e RSCsPN devido ao pequeno número de pacientes do último. Além disso, os grupos RSC não foram pareados, o que determinou algumas diferenças nas características demográficas, especialmente quanto à média de anos de estudo. Ainda, para avaliação da sialometria não foram levadas em consideração medicações utilizadas pelos pacientes que sabidamente interferem com a qualidade e quantidade salivares, como antihipertensivos, anticolinérgicos e antidepressivos. 
Entretanto, trata-se de estudo pioneiro na temática de halitose e RSC que propõe perspectivas interessantes para estudos futuros.

Assim, observou-se que os pacientes com RSC apresentaram maior prevalência de halitose quando comparados à população normal, entretanto o mau odor bucal é originado de outros odorivetores que não os compostos sulfurados voláteis. Mais pesquisas são necessárias a fim de se confirmarem os achados deste estudo, identificar os compostos orgânicos responsáveis pela halitose na RSC, elucidar os mecanismos fisiopatogênicos envolvidos na relação entre RSC e halitose e avaliar a resolução da halitose após instituição do tratamento adequado para RSC. 


\section{CONCLUSÃO}

- A prevalência de halitose no grupo RSC foi 4 vezes superior à do grupo controle ao teste organoléptico e este resultado é estatisticamente significante.

- As concentrações de CSV oral e nasal sem diferença estatisticamente significante indica que a avaliação com Halimeter $^{\circledR}$ em FFNN no presente estudo não mostrou utilidade no rastreio ou seguimento dos pacientes com RSC. 


\section{REFERÊNCIAS BIBLIOGRÁFICAS}

1. Bhattacharyya N. Contemporary assessment of the disease burden of sinusitis. Am J Rhinol Allergy. 2009;23(4):392-5.

2. Anand VK. Epidemiology and economic impact of rhinosinusitis. Ann Otol Rhinol Laryngol Suppl. 2004;193:3-5.

3. Bhattacharyya N. Incremental health care utilization and expenditures for chronic rhinosinusitis in the United States. Ann Otol Rhinol Laryngol. 2011;120(7):423-7.

4. Fokkens WJ, Lund V, Mullol J. European position paper on rhinosinusitis and nasal polyps 2012. Rhinology. 2012;45(SUPPL. 20):1-136.

5. Orlandi RR, Kingdom TT, Hwang PH, Smith TL, Alt JA, Baroody FM, et al. International Consensus Statement on Allergy and Rhinology: Rhinosinusitis. Int Forum Allergy Rhinol. 2016;6(S1):S22-209.

6. Meltzer EO, Hamilos DL, Hadley JA, Lanza DC, Marple BF, Nicklas RA, et al. Rhinosinusitis: Establishing definitions for clinical research and patient care. J Allergy Clin Immunol. 2004;114(6):S155-212.

7. Falcão DP, Vieira CN, Batista de Amorim RF. Breaking paradigms: a new definition for halitosis in the context of pseudo-halitosis and halitophobia. $J$ Breath Res. 2012;6(1):017105.

8. Porter SR, Scully C. Oral malodour (halitosis). BMJ. 2006;333(7569):632-5.

9. Petrini M, Costacurta M, Ferrante M, Trentini P, Docimo R, Spoto G. Association between the organoleptic scores, oral condition and salivary $\beta$ galactosidases in children affected by halitosis. Int J Dent Hyg. 2014;12(3):213-8.

10. Tangerman A, Winkel EG. Intra- and extra-oral halitosis: Finding of a new form of extra-oral blood-borne halitosis caused by dimethyl sulphide. J Clin Periodontol. 2007;34(9):748-55.

11. Nadanovsky P, Carvalho LBM, Ponce de Leon A. Oral malodour and its association with age and sex in a general population in Brazil. Oral Dis. 2007;13(1):105-9. 
12. Scully C, Greenman J. Halitology (breath odour: Aetiopathogenesis and management). Oral Dis. 2012;18(4):333-45.

13. Bhattacharyya N, Orlandi RR, Grebner J, Martinson M. Cost Burden of Chronic Rhinosinusitis: A Claims Based Study. Otolaryngol - Head Neck Surg. 2011;144(3):440-5.

14. Rosenfeld RM, Piccirillo JF, Chandrasekhar SS, Brook I, Ashok Kumar K, Kramper M, et al. Clinical Practice Guideline (Update): Adult Sinusitis. Otolaryngol - Head Neck Surg. 2015;152(2 suppl):S1-39.

15. [No authors listed]. Report of the Rhinosinusitis Task Force Committee Meeting. Alexandria, Virginia, August 17, 1996. Otolaryngol - Head Neck Surg. 1997;117(3 Pt 2):S1-68.

16. Meltzer EO, Hamilos DL, Hadley JA, Lanza DC, Marple BF, Nicklas RA, et al. Rhinosinusitis: Developing guidance for clinical trials. Otolaryngol - Head Neck Surg. 2006;135(5 Suppl):S31-80.

17. Bhattacharyya N. Chronic Rhinosinusitis: Is the Nose Really Involved? Am J Rhinol. 2001;15(3):169-73.

18. Van Crombruggen K, Van Bruaene N, Holtappels G, Bachert C. Chronic sinusitis and rhinitis: Clinical terminology chronic rhinosinusitis further supported. Rhinology. 2010;48(1):54-8.

19. Akdis CA, Bachert C, Cingi C, Dykewicz MS, Hellings PW, Naclerio RM, et al. Endotypes and phenotypes of chronic rhinosinusitis: A PRACTALL document of the European Academy of Allergy and Clinical Immunology and the American Academy of Allergy, Asthma \& Immunology. J Allergy Clin Immunol. Elsevier Ltd; 2013;131(6):1479-90.

20. Pilan RR de M, Pinna FDR, Bezerra TFP, Mori RL, Padua FGDM, Bento RF, et al. Prevalence of chronic rhinosinusitis in São Paulo. Rhinology. 2012;50:12938.

21. Shashy RG, Moore EJ, Weaver A, LJ MI, V B, DK C, et al. Prevalence of the Chronic Sinusitis Diagnosis in Olmsted County, Minnesota. Arch Otolaryngol Neck Surg. American Medical Association; 2004;130(3):320.

22. Hastan D, Fokkens WJ, Bachert C, Newson RB, Bislimovska J, Bockelbrink A, 
et al. Chronic rhinosinusitis in Europe -an underestimated disease. A GA ${ }^{2}$ LEN study. Allergy. 2011;66(9):1216-23.

23. Schiller JS, Lucas JW, Ward BW, Peregoy J a. Summary health statistics for u.s. Adults: national health interview survey, 2012. Vital Heal Stat 10. 2012;(252):1-171.

24. Bhattacharyya N. Functional limitations and workdays lost associated with chronic rhinosinusitis and allergic rhinitis. Am J Rhinol Allergy. 2012;26(2):1202.

25. Chen $Y$, Dales R, Lin M. The Epidemiology of Chronic Rhinosinusitis in Canadians. Laryngoscope. John Wiley \& Sons, Inc.; 2003;113(7):1199-205.

26. Ciprandi G, Tosca MA, Signori A, Cirillo I. Visual analogue scale assessment of nasal obstruction might define patients candidates to spirometry. Rhinology. 2011;49(3):2001.

27. Guillemin F, Bombardier C, Beaton D. Cross-cultural adaptation of healthrelated quality of life measures: literature review and proposed guidelines. $J$ Clin Epidemiol. 1993;46(12):1417-32.

28. Piccirillo JF, Merritt MG, Richards ML. Psychometric and clinimetric validity of the 20-Item Sino-Nasal Outcome Test (SNOT-20). Otolaryngol Head Neck Surg. 2002;126(1):41-7.

29. Ware JE, Sherbourne CD. The MOS 36-item short-form health survey (SF-36).

I. Conceptual framework and item selection. Med Care. 1992;30(6):473-83.

30. Hopkins C. Patient reported outcome measures in rhinology. Rhinology. 2009;47(1):10-7.

31. Hopkins C, Gillett S, Slack R, Lund VJ, Browne JP. Psychometric validity of the 22-item Sinonasal Outcome Test. Clin Otolaryngol. 2009;34(5):447-54.

32. Kosugi EM, Chen VG, Fonseca VMG Da, Cursino MMP, Mendes Neto JA, Gregório LC. Translation, cross-cultural adaptation and validation of SinoNasal Outcome Test (SNOT): 22 to Brazilian Portuguese. Braz J Otorhinolaryngol. 2011;77(5):663-9.

33. Bhattacharyya N. The economic burden and symptom manifestations of 
chronic rhinosinusitis. Am J Rhinol. 2003;17(1):27-32.

34. Au J, Rudmik L. Cost of outpatient endoscopic sinus surgery from the perspective of the Canadian government: a time-driven activity-based costing approach. Int Forum Allergy Rhinol. 2013;3(9):748-54.

35. Bhattacharyya N. Assessing the additional disease burden of polyps in chronic rhinosinusitis. Ann Otol Rhinol Laryngol. 2009;118(3):185-9.

36. Anzai $Y$, Jarvik JG, Sullivan SD, Hollingworth $W$. The cost-effectiveness of the management of acute sinusitis. Am J Rhinol. 2007;21(4):444-51.

37. Rudmik L, Smith TL, Schlosser RJ, Hwang PH, Mace JC, Soler ZM. Productivity costs in patients with refractory chronic rhinosinusitis. Laryngoscope. 2014;124(9):2007-12.

38. Soler ZM, Wittenberg E, Schlosser RJ, MacE JC, Smith TL. Health state utility values in patients undergoing endoscopic sinus surgery. Laryngoscope. 2011;121(12):2672-8.

39. Remenschneider AK, D’Amico L, Gray ST, Holbrook EH, Gliklich RE, Metson $R$. The EQ-5D: a new tool for studying clinical outcomes in chronic rhinosinusitis. Laryngoscope. 2015;125(1):7-15.

40. Chester AC, Sindwani R, Smith TL, Bhattacharyya N. Fatigue Improvement Following Endoscopic Sinus Surgery: A Systematic Review and Meta-Analysis. Laryngoscope. John Wiley \& Sons, Inc.; 2008;118:730-9.

41. Alt JA, Smith TL, Mace JC, Soler ZM. Sleep Quality and Disease Severity in Patients with Chronic Rhinosinusitis. Laryngoscope. 2013;123(10):2364-70.

42. Centers for Disease Control and Prevention (CDC). Current depression among adults - United States, 2006 and 2008. MMWR Morb Mortal Wkly Rep. 2010;59(38):1229-35.

43. Van Bruaene N, Bachert C. Tissue remodeling in chronic rhinosinusitis. Curr Opin Allergy Clin Immunol. 2011;11(1):8-11.

44. Otto BA, Wenzel SE. The role of cytokines in chronic rhinosinusitis with nasal polyps. Curr Opin Otolaryngol Head Neck Surg. 2008;16(3):270-4.

45. Figueiredo CR, Silva IDCG, Weckx LLM. Inflammatory genes in nasal 
polyposis. Curr Opin Otolaryngol Head Neck Surg. 2008;16(1):18-21.

46. Zhang N, Van Zele T, Perez-Novo C, Van Bruaene N, Holtappels G, DeRuyck $\mathrm{N}$, et al. Different types of T-effector cells orchestrate mucosal inflammation in chronic sinus disease. J Allergy Clin Immunol. 2008;122(5):961-8.

47. Li C, Shi L, Yan Y, Gordon BR, Gordon WM, Wang DY. Gene expression signatures: A new approach to understanding the pathophysiology of chronic rhinosinusitis. Curr Allergy Asthma Rep. 2013;13(2):209-17.

48. Huvenne W, van Bruaene N, Zhang N, van Zele T, Patou J, Gevaert P, et al. Chronic rhinosinusitis with and without nasal polyps: what is the difference? Curr Allergy Asthma Rep. 2009;9(3):213-20.

49. Voegels RL, de Melo Pádua FG. Expression of interleukins in patients with nasal polyposis. Otolaryngol Head Neck Surg. 2005;132(4):613-9.

50. Van Drunen CM, Mjösberg JM, Segboer CL, Cornet ME, Fokkens WJ. Role of innate immunity in the pathogenesis of chronic rhinosinusitis: Progress and new avenues. Curr Allergy Asthma Rep. 2012;12(2):120-6.

51. Kern R, Conley D, Waish W, Chandra R, Kato A, Ph D, et al. Perspectives on the etiology of chronic rhinosinusitis: An immune barrier hypothesis. Am J Rhinol. 2008;22(6):549-59.

52. Lane A, Truong-Tran Q, Schleimer RP. Altered expression of genes associated with innate immunity and inflammation in recalcitrant rhinosinusitis with polyps. Am J Rhinol. 2006;20(2):138-44.

53. Reh D, Wang Y, Ramanathan M, Lane A. Treatment-recalcitrant chronic rhinosinusitis with polyps is associated with altered epithelial cell expression of interleukin-33. Am J Rhinol Allergy. 2010;24(2):105-9.

54. Chin D, Harvey RJ. Nasal polyposis: an inflammatory condition requiring effective anti-inflammatory treatment. Curr Opin Otolaryngol Head Neck Surg. 2013;21(1):23-30.

55. Sakano E, Ribeiro AF, Barth L, Neto AC, Ribeiro JD. Nasal and paranasal sinus endoscopy, computed tomography and microbiology of upper airways and the correlations with genotype and severity of cystic fibrosis. Int J Pediatr Otorhinolaryngol. 2007;71(1):41-50. 
56. Wang X, Kim J, McWilliams R, Cutting GR. Increased prevalence of chronic rhinosinusitis in carriers of a cystic fibrosis mutation. ArchOtolaryngolHead Neck Surg. 2005;131(3):237-40.

57. Park C-S, Cho J-H, Park Y-J. Toll-like receptor 2 gene polymorphisms in a Korean population: association with chronic rhinosinusitis. Otolaryngol Head Neck Surg. 2011;144(1):96-100.

58. Kosugi EM, de Camargo-Kosugi CM, Hirai ER, Mendes-Neto JA, Gregorio LC, Guerreiro-da-Silva ID, et al. Interleukin-6 -174 G/C promoter gene polymorphism in nasal polyposis and asthma. Rhinology. 2013;51(1):70-6.

59. Lee RJ, Xiong G, Kofonow JM, Chen B, Lysenko A, Jiang P, et al. T2R38 taste receptor polymorphisms underlie susceptibility to upper respiratory infection. J Clin Invest. 2012;122(11):4145-59.

60. Lee R, Kofonow J, Rosen P, Siebert A, Chen B, Doghramii L, et al. Bitter and sweet taste receptors regulate human upper respiratory innate immunity. J Clin Invest. 2014;124(3):1393-405.

61. Chiu AG, Chen B, Palmer JN, O'Malley BW, Cohen NA. Safety evaluation of sinus surfactant solution on respiratory cilia function. Int Forum Allergy Rhinol. 2011;1(4):280-3.

62. Antunes MB, Gudis DA, Cohen NA. Epithelium, cilia, and mucus: their importance in chronic rhinosinusitis. Immunol Allergy Clin North Am. 2009;29(4):631-43.

63. Chen B, Shaari J, Claire SE, Palmer JN, Chiu AG, Kennedy DW, et al. Altered sinonasal ciliary dynamics in chronic rhinosinusitis. Am J Rhinol. 2006;20(3):325-9.

64. Davis SS, Illum L. Absorption enhancers for nasal drug delivery. Clin Pharmacokinet. 2003;42(13):1107-28.

65. Gudis D, Zhao KQ, Cohen NA. Acquired cilia dysfunction in chronic rhinosinusitis. Am J Rhinol Allergy. 2012;26(1):1-6.

66. Gudis DA, Cohen NA. Cilia dysfunction. Otolaryngol Clin North Am. 2010;43(3):461-72, vii. 
67. Kanthakumar K, Taylor G, Tsang KWT, Cundell DR, Rutman A, Smith S, et al. Mechanisms of action of Pseudomonas aeruginosa pyocyanin on human ciliary beat in vitro. Infect Immun. 1993;61(7):2848-53.

68. Dejima K, Randell SH, Stutts J, Senior BA, Boucher RC. Potential Role of Abnormal Ion Transport in the Pathogenesis of Chronic Sinusitis. Arch Otolaryngol Neck Surg. 2006;132:1352-62.

69. Li YY, Li CW, Chao SS, Yu FG, Yu XM, Liu J, et al. Impairment of cilia architecture and ciliogenesis in hyperplastic nasal epithelium from nasal polyps. J Allergy Clin Immunol. 2014;134(6):1282-92.

70. Lai Y, Chen B, Shi J, Palmer JN, Kennedy DW, Cohen NA. Inflammationmediated upregulation of centrosomal protein 110, a negative modulator of ciliogenesis, in patients with chronic rhinosinusitis. J Allergy Clin Immunol. 2011;128(6):1207-15.e1.

71. Chen B, Antunes MB, Claire SE, Palmer JN, Chiu AG, Kennedy DW, et al. Reversal of chronic rhinosinusitis-associated sinonasal ciliary dysfunction. Am J Rhinol. 2007;21(3):346-53.

72. Scadding GK, Lund VJ, Darby YC. The effect of long-term antibiotic therapy upon ciliary beat frequency in chronic rhinosinusitis. J Laryngol Otol. 1995;109(1):24-6.

73. Caughey RJ, Jameson MJ, Gross CW, Han JK. Anatomic risk factors for sinus disease: fact or fiction? Am J Rhinol. 2005;19(4):334-9.

74. Jain R, Stow N, Douglas R. Comparison of anatomical abnormalities in patients with limited and diffuse chronic rhinosinusitis. Int Forum Allergy Rhinol. 2013;3(6):493-6.

75. Orlandi RR. A systematic analysis of septal deviation associated with rhinosinusitis. Laryngoscope. 2010;120(8):1687-95.

76. Fadda GL, Rosso S, Aversa S, Petrelli A, Ondolo C, Succo G. Multiparametric statistical correlations between paranasal sinus anatomic variations and chronic rhinosinusitis. Acta Otorhinolaryngol Ital. 2012;32(4):244-51.

77. Nouraei SAR, Elisay AR, Dimarco A, Abdi R, Majidi H, Madani SA, et al. Variations in paranasal sinus anatomy: implications for the pathophysiology of 
chronic rhinosinusitis and safety of endoscopic sinus surgery. J Otolaryngol Head Neck Surg. 2009;38(1):32-7.

78. Cho JH, Park M-S, Chung YS, Hong S-C, Kwon KH, Kim JK. Do anatomic variations of the middle turbinate have an effect on nasal septal deviation or paranasal sinusitis? Ann Otol Rhinol Laryngol. 2011;120(9):569-74.

79. Prasad S, Varshney S, Bist SS, Mishra S, Kabdwal N. Correlation Study Between Nasal Septal Deviation and Rhinosinusitis. Indian J Otolaryngol Head Neck Surg. 2013;65(4):363-6.

80. Cho GS, Moon BJ, Lee BJ, Gong CH, Kim NH, Kim YS, et al. High rates of detection of respiratory viruses in the nasal washes and mucosae of patients with chronic rhinosinusitis. J Clin Microbiol. 2013;51(3):979-84.

81. Lima Junior JT. Prevalência e sazonalidade dos vírus respiratórios na rinossinusite crônica com e sem pólipos nasais e sua influência na celularidade da mucosa e dos pólipos nasais. [tese] São Paulo Univ São Paulo. 2013;

82. Isaacs S, Fakhri S, Luong A, Citardi MJ. A meta-analysis of topical amphotericin $B$ for the treatment of chronic rhinosinusitis. Int Forum Allergy Rhinol. 2011;1(4):250-4.

83. Fokkens WJ, Ebbens F, van Drunen CM. Fungus: A Role in Pathophysiology of Chronic Rhinosinusitis, Disease Modifier, A Treatment Target, or No Role at All? Immunol Allergy Clin North Am. 2009;29(4):677-88.

84. Boase S, Foreman A, Cleland E, Tan L, Melton-Kreft R, Pant H, et al. The microbiome of chronic rhinosinusitis: culture, molecular diagnostics and biofilm detection. BMC Infect Dis. 2013;13:210.

85. Hwang PH. Staph aureus has long been recognized as being more prevalent in cultures from patients with chronic rhinosinusitis (CRS) compared to those with acute rhinosinusitis. Int Forum Allergy Rhinol. 2013;3(2):81-2.

86. Wang M, Shi P, Yue Z, Chen B, Zhang H, Zhang D, et al. Superantigens and the expression of $\mathrm{T}$-cell receptor repertoire in chronic rhinosinusitis with nasal polyps. Acta Otolaryngol. 2008;128(8):901-8.

87. Wood AJ, Fraser JD, Swift S, Patterson-Emanuelson EAC, Amirapu S, 
Douglas RG. Intramucosal bacterial microcolonies exist in chronic rhinosinusitis without inducing a local immune response. Am J Rhinol Allergy. 2012;26(4):265-70.

88. Foreman A, Holtappels G, Psaltis AJ, Jervis-Bardy J, Field J, Wormald P-J, et al. Adaptive immune responses in Staphylococcus aureus biofilm-associated chronic rhinosinusitis. Allergy. 2011;66(11):1449-56.

89. Ferguson BJ, Stolz DB. Demonstration of Biofilm in Human Bacterial Chronic Rhinosinusitis. Am J Rhinol. 2005;19(5):452-7.

90. Xu KD, McFeters GA, Stewart PS. Biofilm resistance to antimicrobial agents. Microbiol. 2000;146(3):547-9.

91. Costerton JW, Stewart PS, Greenberg EP. Bacterial biofilms: a common cause of persistent infections. Science (80- ). 1999;284(5418):1318-22.

92. Hekiert AM, Kofonow JM, Doghramji L, Kennedy DW, Chiu AG, Palmer JN, et al. Biofilms correlate with $\mathrm{TH} 1$ inflammation in the sinonasal tissue of patients with chronic rhinosinusitis. Otolaryngol - Head Neck Surg. 2009;141(4):448-53.

93. Foreman A, Wormald P-J. Different biofilms, different disease? A clinical outcomes study. Laryngoscope. 2010;120(8):1701-6.

94. Bachert C, Pawankar R, Zhang L, Bunnag C, Fokkens WJ, Hamilos DL, et al. ICON : chronic rhinosinusitis. World Allergy Organ J. 2014;7(1):25.

95. Hwang PH, Irwin SB, Griest SE, Caro JE, Nesbit GM. Radiologic correlates of symptom-based diagnostic criteria for chronic rhinosinusitis. Otolaryngol -head neck Surg. 2003;128(4):489-96.

96. Pynnonen M, Fowler K, Terrell JE. Clinical predictors of chronic rhinosinusitis. Am J Rhinol. 2007;21(2):159-63.

97. Bhattacharyya N, Lee LN. Evaluating the diagnosis of chronic rhinosinusitis based on clinical guidelines and endoscopy. Otolaryngol - Head Neck Surg. 2010;143(1):147-51.

98. Malekzadeh S, Hamburger MD, Whelan PJ, Biedlingmaier JF, Baraniuk JN. Density of middle turbinate subepithelial mucous glands in patients with chronic rhinosinusitis. Otolaryngol - Head Neck Surg. 2002;127(3):190-5. 
99. Kennedy DW, Wright ED, Goldberg AN. Objective and subjective outcomes in surgery for chronic sinusitis. Laryngoscope. 2000;110(3 Pt 3):29-31.

100. Bhattacharyya N. Clinical and symptom criteria for the accurate diagnosis of chronic rhinosinusitis. Laryngoscope. 2006;116(7 Pt 2 Suppl 110):1-22.

101. Mygind N. Allergic rhinitis. Chem Immunol Allergy. 2014;100:62-8.

102. Brozek JL, Bousquet J, Baena-Cagnani CE, Bonini S, Canonica GW, Casale TB, et al. Allergic Rhinitis and its Impact on Asthma (ARIA) guidelines: 2010 Revision. J Allergy Clin Immunol. 2010;126(3):466-76.

103. Lal D, Rounds A, Dodick DW. Comprehensive management of patients presenting to the otolaryngologist for sinus pressure, pain, or headache. Laryngoscope. 2015;125(2):303-10.

104. Kari E, DelGaudio JM. Treatment of sinus headache as migraine: the diagnostic utility of triptans. Laryngoscope. 2008;118(12):2235-9.

105. Banks CA, Palmer JN, Chiu AG, O'Malley BW, Woodworth BA, Kennedy DW. Endoscopic closure of CSF rhinorrhea: 193 cases over 21 years. Otolaryngol Head Neck Surg. 2009;140(6):826-33.

106. Scadding GK, Durham SR, Mirakian R, Jones NS, Drake-Lee AB, Ryan D, et al. BSACl guidelines for the management of rhinosinusitis and nasal polyposis. Clin Exp Allergy. 2008;38(2):260-75.

107. Desrosiers M, Evans GA, Keith PK, Wright ED, Kaplan A, Bouchard J, et al. Canadian clinical practice guidelines for acute and chronic rhinosinusitis. $J$ Otolaryngol Head Neck Surg. 2011;40 Suppl 2:S99-193.

108. Nagi MM, Desrosiers MY. Algorithms for management of chronic rhinosinusitis. Otolaryngol Clin North Am. 2005;38(6):1137-41, vii.

109. Amine M, Lininger L, Fargo KN, Welch KC. Outcomes of endoscopy and computed tomography in patients with chronic rhinosinusitis. Int Forum Allergy Rhinol. 2013;3(1):73-9.

110. Tan BK, Lu G, Kwasny MJ, Hsueh WD, Shintani-Smith S, Conley DB, et al. Effect of symptom-based risk stratification on the costs of managing patients with chronic rhinosinusitis symptoms. Int Forum Allergy Rhinol. 
2013;3(11):933-40.

111. Grobler A, Weitzel EK, Buele A, Jardeleza C, Cheong YC, Field J, et al. Preand postoperative sinus penetration of nasal irrigation. Laryngoscope. 2008;118(11):2078-81.

112. Harvey R, Hannan SA, Badia L, Scadding G. Nasal saline irrigations for the symptoms of chronic rhinosinusitis. Cochrane database Syst Rev. 2007;(3):CD006394.

113. Rudmik L, Hoy M, Schlosser RJ, Harvey RJ, Welch KC, Lund V, et al. Topical therapies in the management of chronic rhinosinusitis: an evidence-based review with recommendations. Int Forum Allergy Rhinol. 2013;3(4):281-98.

114. Bhalla RK, Payton K, Wright ED. Safety of budesonide in saline sinonasal irrigations in the management of chronic rhinosinusitis with polyposis: lack of significant adrenal suppression. J Otolaryngol Head Neck Surg. 2008;37(6):821-5.

115. Welch KC, Thaler ER, Doghramji LL, Palmer JN, Chiu AG. The effects of serum and urinary cortisol levels of topical intranasal irrigations with budesonide added to saline in patients with recurrent polyposis after endoscopic sinus surgery. Am J Rhinol Allergy. 2010;24(1):26-8.

116. Yaegaki K, Sanada K. Biochemical and clinical factors influencing oral malodor in periodontal patients. J Periodontol. 1992;63(9):783-9.

117. Jardim JJ, Alves LS, Maltz M. The history and global market of oral home-care products. Braz Oral Res. 2009;23 Suppl 1:17-22.

118. Rosenberg M, McCulloch CA. Measurement of oral malodor: current methods and future prospects. J Periodontol. 1992;63(9):776-82.

119. Brunetti MC, Fernandes MI, de Moraes RGB. Fundamentos da Periodontia. In: Fundamentos da Periodontia: Teoria e prática. 1 ed. São Paulo: Artes Médicas; 2007. p. 1-18.

120. Yaegaki K, Coil JM. Examination, classification, and treatment of halitosis; clinical perspectives. J Can Dent Assoc. 2000 May;66(5):257-61.

121. Tomás Carmona I, Limeres Posse J, Diz Dios P, Fernández Feijoo J, Vázquez 
García E. Extraoral etiology of halitosis. Med oral. 2001;6(1):40-7.

122. Tangerman A. Halitosis in medicine: a review. Int Dent J. 2002;52 Suppl 3:201-6.

123. Rayman S, Almas K. Halitosis among racially diverse populations: an update. Int J Dent Hyg. 2008;6(1):2-7.

124. Liu XN, Shinada K, Chen XC, Zhang BX, Yaegaki K, Kawaguchi Y. Oral malodor-related parameters in the Chinese general population. J Clin Periodontol. 2006;33(1):31-6.

125. Outhouse TL, Al-Alawi R, Fedorowicz Z, Keenan J V. Tongue scraping for treating halitosis. Cochrane database Syst Rev. 2006;(2):CD005519.

126. Miyazaki H, Sakao S, Katoh $\mathrm{Y}$, Takehara T. Correlation between volatile sulphur compounds and certain oral health measurements in the general population. J Periodontol. 1995;66(8):679-84.

127. Arseculeratne G, Wong AKC, Goudie DR, Ferguson J. Trimethylaminuria (fishodor syndrome): a case report. Arch Dermatol. 2007;143(1):81-4.

128. van den Velde S, Quirynen M, van Hee P, van Steenberghe D. Halitosis associated volatiles in breath of healthy subjects. J Chromatogr B Analyt Technol Biomed Life Sci. 2007;853(1-2):54-61.

129. Loesche WJ, Kazor C. Microbiology and treatment of halitosis. Periodontol 2000. 2002;28(1):256-79.

130. Scully C, Greenman J. Halitosis (breath odor). Periodontol 2000. 2008;48(1):66-75.

131. Tonzetich J. Production and origin of oral malodor: a review of mechanisms and methods of analysis. J Periodontol. 1977;48(1):13-20.

132. Goldberg S, Kozlovsky A, Gordon D, Gelernter I, Sintov A, Rosenberg M. Cadaverine as a putative component of oral malodor. J Dent Res. 1994;73(6):1168-72.

133. Nakano Y, Yoshimura M, Koga T. Methyl mercaptan production by periodontal bacteria. Int Dent J. 2002;52 Suppl 3:217-20.

134. Bollen CM, Beikler T. Halitosis: the multidisciplinary approach. Int J Oral Sci. 
2012;4(2):55-63.

135. Greenman J, Lenton P, Seemann R, Nachnani S. Organoleptic assessment of halitosis for dental professionals--general recommendations. J Breath Res. 2014;8:17102.

136. Ueno M, Shinada K, Yanagisawa T, Mori C, Yokoyama S, Furukawa S, et al. Clinical oral malodor measurement with a portable sulfide monitor. Oral Dis. 2008;14(3):264-9.

137. Brunner F, Kurmann M, Filippi A. The correlation of organoleptic and instrumental halitosis measurements. Schweizer Monatsschrift fur Zahnmedizin. 2010;120(5):402-8.

138. Lee PPC, Mak WY, Newsome P. The aetiology and treatment of oral halitosis: An update. Hong Kong Med J. 2004;10(6):414-8.

139. Vieira CN, Falcão DP, Faber J, Nunes F de P, Leal SC. Avaliação da condição periodontal e da presença de biofilme lingual como indicadores de risco para halitose. Rev Periodontia. 2010;20(2):53-60.

140. Kapoor U, Sharma G, Juneja M, Nagpal A. Halitosis: Current concepts on etiology, diagnosis and management. Eur J Dent. 2016;10(2):292-300.

141. Ueno M, Takeuchi S, Takehara S, Kawaguchi Y. Saliva viscosity as a potential risk factor for oral malodor. Acta Odontol Scand. 2014;72(8):1005-9.

142. Falcão DP, Mota LMH da, Pires AL, Bezerra ACB. Sialometry: aspects of clinical interest. Rev Bras Reumatol. 2013;53(6):525-31.

143. Ericsson Y, Hardwick L. Individual diagnosis, prognosis and counselling for caries prevention. Caries Res. 1978;12 Suppl 1:94-102.

144. Ferguson M. Rhinosinusitis in oral medicine and dentistry. Aust Dent J. 2014;59(3):289-95.

145. Motta LJ, Bachiega JC, Guedes CC, Laranja LT, Bussadori SK. Association between halitosis and mouth breathing in children. Clinics. 2011;66(6):939-42.

146. Lanza DC. Diagnosis of chronic rhinosinusitis. Ann Otol Rhinol Laryngol Suppl. 2004;193:10-4.

147. Ainamo J, Bay I. Problems and proposals for recording gingivitis and plaque. 
Int Dent J. 1975;25(4):229-35.

148. Faul F, Erdfelder E, Lang A-G, Buchner A. G*Power 3: a flexible statistical power analysis program for the social, behavioral, and biomedical sciences. Behav Res Methods. 2007;39(2):175-91.

149. Aizawa F, Kishi M, Moriya T, Takahashi M, Inaba D, Yonemitsu M. The analysis of characteristics of elderly people with high VSC level. Oral Dis. 2005;11(SUPPL. 1):80-2.

150. Leal SC, Bittar J, Portugal A, Falcão DP, Faber J, Zanotta P. Medication in elderly people: Its influence on salivary pattern, signs and symptoms of dry mouth. Gerodontology. 2010;27(2):129-33.

151. Lee RU, Stevenson DD. Aspirin-Exacerbated Respiratory Disease: Evaluation and Management. Allergy, Asthma Immunol Res. 2011;3(1):3.

152. Bornstein MM, Kislig K, Hoti BB, Seemann R, Lussi A. Prevalence of halitosis in the population of the city of Bern, Switzerland: a study comparing selfreported and clinical data. Eur J Oral Sci. 2009 Jun;117(3):261-7.

153. Penala S, Kalakonda B, Pathakota KR, Jayakumar A, Koppolu P, Lakshmi BV, et al. Efficacy of local use of probiotics as an adjunct to scaling and root planing in chronic periodontitis and halitosis: A randomized controlled trial. $\mathrm{J}$ Res Pharm Pract. 2016;5(2):86-93.

154. Nibali L, Di lorio A, Onabolu O, Lin G-H. Periodontal infectogenomics: systematic review of associations between host genetic variants and subgingival microbial detection. J Clin Periodontol. 2016;

155. Sato H, Ohkushi T, Kaizu T, Tsunoda M, Sato T. A study of the mechanism of halitosis occurrence in periodontal patients. Bull Tokyo Dent Coll. 1980;21(4):271-8. 


\section{APÊNDICES}

\subsection{APÊNDICE 1}

\section{TERMO DE CONSENTIMENTO LIVRE E ESCLARECIDO}

\section{Dados de identificação}

Título do Projeto: "Análise dos níveis de compostos sulfurados voláteis e sua relação com rinossinusite crônica".

Pesquisador Responsável: Dr Rivadávio Amorim / Dra Priscila Carvalho Miranda Orientador: Dr Rivadávio Amorim / Dr Márcio Nakanishi

\section{Instituição a que pertencem os Pesquisadores:}

Hospital Universitário de Brasília, Faculdade de Medicina, Universidade de Brasília Telefone para contato: (61) 3448-5580

Comitê de Ética em Pesquisa da Faculdade de Medicina da Universidade de Brasília. Telefone de contato: 3107-1918

Nome do voluntário:

Idade: anos

R.G.

O(A) Sr. (a) está sendo convidado(a) a participar do projeto de pesquisa "Análise dos níveis de compostos sulfurados voláteis e sua relação com rinossinusite crônica". Esclarecemos que este projeto vai verificar a relação entre a sinusite crônica e o mau hálito. Tal estudo trará benefícios para os pacientes, uma vez que o esclarecimento de fatores envolvidos na doença permite uma melhor avaliação, seguimento e possibilidade terapêutica para os pacientes. Informamos ainda se que o(a) senhor(a) não quiser participar da presente pesquisa isto não acarretará nenhum prejuízo na conduta ou investigação diagnóstica de sua doença.

Durante a sua consulta no ambulatório será feita a avaliação do hálito por meio de um teste com examinador e com um aparelho que capta o ar que sai da boca e do nariz e analisa alguns compostos químicos. Os dados do seu prontuário poderão ser consultados pela equipe para fins de pesquisa, não interferindo nas condutas ou tratamento.

Não haverá nenhuma complicação para o(a) senhor(a) a não ser um pequeno incômodo pela inserção da sonda no vestíbulo nasal ("entrada"do nariz).

Em caso de dúvidas acerca dos procedimentos, riscos, benefícios e outros assuntos relacionados com a pesquisa, o(a) voluntário(a) deve procurar o pesquisador responsável pelo número de telefone acima, a fim de saná-las.

A participação neste estudo é voluntária e a qualquer momento este consentimento poderá ser retirado pelo voluntário. As informações obtidas são confidenciais e serão publicadas anonimamente. Os nomes dos participantes serão mantidos em absoluto sigilo, não acarretando, assim, prejuízos à privacidade dos mesmos.

$\mathrm{Eu}, \ldots$ fui informado e participo voluntariamente desta pesquisa.

Brasília, de de

Nome e assinatura do sujeito ou responsável $\overline{\text { Nome e assinatura da Testemunha }}$

Nome e assinatura do pesquisador responsável 
10.2. APÊNDICE 2

\section{PROTOCOLO HALITOSE E RSC}

\section{IDENTIFICAÇÃO}

Nome: Data:

DN:_/_____ Idade atual: Gênero: ( )F ( )M

Raça: ( ) Branca ( ) Negra ( ) Parda ( ) Amarela

Escolaridade: ( ) Ensino fundamental incompleto ( ) Ensino fundamental completo
( ) Ensino médio incompleto
( ) Ensino médio completo

( ) Ensino superior incompleto ( ) Ensino superior completo

Total de anos de estudo (excluindo repetências):

Estado civil: ( ) Solteiro

( )separado/divorciado ( ) viúvo

$\mathrm{Rg}:$

Tel:

E-mail:

DEFINIÇÃO CLÍNICA

$\begin{array}{lll}\text { ( ) RSCCPN } & \text { ( ) RSCsPN }\end{array}$

\begin{tabular}{|l|l|l|llllllllll|}
\hline SINTOMAS & SIM & NÃO & VAS & & & & & & & & & \\
\hline Obstrução nasal & & & 1 & 2 & 3 & 4 & 5 & 6 & 7 & 8 & 9 & 10 \\
\hline Descarga nasal (ant/post) & & & 1 & 2 & 3 & 4 & 5 & 6 & 7 & 8 & 9 & 10 \\
\hline Dor facial / Cefaléia & & & 1 & 2 & 3 & 4 & 5 & 6 & 7 & 8 & 9 & 10 \\
\hline Hiposmia & & & 1 & 2 & 3 & 4 & 5 & 6 & 7 & 8 & 9 & 10 \\
\hline
\end{tabular}

O quão incômodos são os sintomas de rinossinusite? VAS: $\begin{array}{lllllllllll}0 & 1 & 2 & 3 & 4 & 5 & 6 & 7 & 8 & 9 & 10\end{array}$ SNOT-22: / 110

ANTECEDENTES PESSOAIS

\begin{tabular}{|l|l|l|l|}
\hline CONDIÇÕES & SIM & NÃO & OBSERVAÇÕES \\
\hline Sensibilidade ao AAS & & & Respiratória / Cutânea / Outros: \\
\hline Asma/hiperreatividade brônquica & & & Medicações: \\
\hline Alergia & & & \\
\hline Refluxo laringofaríngeo & & & \\
\hline HAS / DM / DLP & & & Medicações: \\
\hline Tabagismo & & & \\
\hline Ant familiares (asma, RSC) & & & \\
\hline Cirurgias nasais prévias & & & \\
\hline
\end{tabular}

EXAME FÍSICO / DEFINIÇÃO ENDOSCÓPICA

\begin{tabular}{|l|l|l|l|}
\hline ACHADOS & SIM & NÃO & Obs \\
\hline Pólipos & & & FND:_ FNE: \\
\hline Descarga mucopurulenta & & & Local: \\
\hline Edema de mucosa & & & Local: \\
\hline Desvio septal & & & Área de Cottle: \\
\hline
\end{tabular}

Classificação de Lindholdt (polipose nasal):

0 = ausência de pólipos

1 = restrito ao $\mathrm{MM}$

2 = pólipo entre a parte sup e inf $\mathrm{Cl}$

3 = pólipo atinge a porção inf $\mathrm{Cl}$ 
AVALIAÇÃO DO HÁLITO

\begin{tabular}{|l|l|l|l|}
\hline CONDIÇÕES & SIM & NÃO & OBSERVAÇÕES \\
\hline Sente o hálito alterado & & & Desde: \\
\hline Halitose confirmada por terceiros & & & ( )companheiro (a) ( )irmão (ã) \\
\hline $\begin{array}{l}\text { Neste momento sente seu hálito } \\
\text { alterado }\end{array}$ & & & \\
\hline $\begin{array}{l}\text { Já procurou outros profissionais } \\
\text { com esta queixa específica }\end{array}$ & & & $\begin{array}{l}\text { Especiliadades: } \\
\text { () gastro () dentista () outros: }\end{array}$ \\
\hline $\begin{array}{l}\text { Este problema alterou seu } \\
\text { comportamento? }\end{array}$ & & \\
\hline $\begin{array}{l}\text { Acha que as pessoas se afastam } \\
\text { enquanto você conversa com elas }\end{array}$ & & & \\
\hline
\end{tabular}

TESTE ORGANOLÉPTICO
( ) 1
( ) 2
( ) 3
( ) 4

ANÁLISE DOS COMPOSTOS SULFURADOS VOLÁTEIS

CSV ORAL:

CSV FNE:

CSV FND:

\section{FLUXO SALIVAR}

SR: $\mathrm{mL} / \mathrm{min} \quad \mathrm{SE}:$ $\mathrm{mL} / \mathrm{min}$

AVALIAÇÃO PERIODONTAL

Presença de doença Periodontal:

( ) SIM

( ) NÃO

Resultado: 


\section{ANEXOS}

\subsection{ANEXO 1}

\section{FACULDADE DE MEDICINA DA UNIVERSIDADE DE BRASÍLIA - UNB}

\section{PARECER CONSUBSTANCIADO DO CEP}

\section{DADOS DO PROJETO DE PESQUISA}

Titulo da Pesquisa: ANÁLISE dOS NIVEIS DE COMPOSTOS SULFURADOS VOLÁTEIS E SUA AELAÇĀO COM RINOSSINUSITE CRONICA

Pesquisador: Rivadtávio Amorim

Área Temática:

Versāo: 2

CAAE: 40348115.0 .0000 .5568

Instituiçấo Proponente: Faculdade de Medicina da Universidade de Brasilia - UNB

Patrocinador Principal: Financiameno Próprio

\section{DADOS DO PARECER}

Número do Parecer: 1.006 .435

Data da Felatoria: 25/03/2015

Apresentaçāo do Projeto:

Comome texto anteriomente inserido

Objetivo da Pesquisa:

Contome texto anteriomente inserido

Avaliaçâo dos Riscos e Beneticios:

Os pesquisadores e as cemais pesquisadoras incluiram as beneficios na redacto co projeto

Comentários e Considerą̧๐es sobre a Pesquisa:

Confarme textb anterioermente inserido.

Consideraçōes sobre os Termos de apresentaçāo obrigstória:

Conforme texts anterioemente inserido.

Recomendą̧ōes:

Contome texto anteriomente inserido.

Conclusōes ou Pendéneiss e Lista de Inadequaçōes:

Os pesquisadores e as demais pesquisadoras atenderam as ponderapjes do Comité de Ética, no parecer de 26 de fevereiro de 2015 .

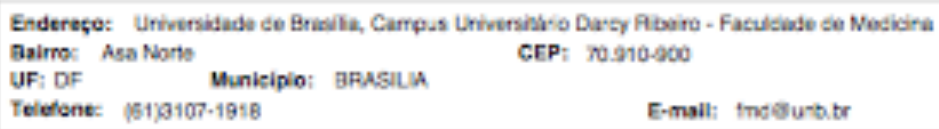




\section{FACULDADE DE MEDICINA DA UNIVERSIDADE DE BRASÍLIA - UNB}

Contrua,bo so Provec: 1006 . 456

Situaçảo do Parecer:

Aprovado

Necessita Apreciação do CONEP:

Nă

Consideraçces Finals a critério do CEP:

O presente projeto foi apreciaco pelo relator que, cansicerou as pendencias previamente apresemadas foram devidamente atentidas e portanto recebem aprovação por este Comitê.

BRASILIA 31 de Março de 2015

Assinade por:

Florêncio Figueiredo Cavaleanti Neto

(Coordenador)

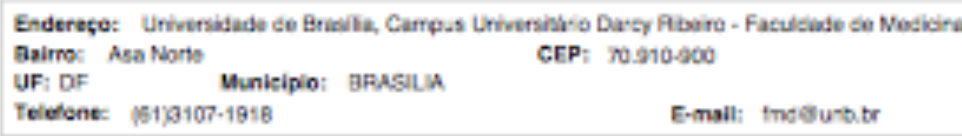




\section{Teste sinonasal SNOT-22}

Realização:
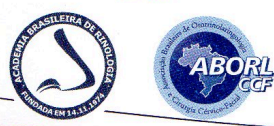

\section{wWw.rinologia.org.br}

Considerando a gravidade dos problemas, classifique a intensidade dos sintomas assinalando:

Necessidade de "assoar" o nariz

Espirros

Nariz "escorrendo"

Tosse

Secreção do nariz indo para a garganta

Secreção grossa saindo do nariz

Sensação de ouvido cheio ou tampado

Tontura ou vertigem

Dor de ouvido

Dor ou pressão no rosto

Dificuldade para dormir

Acordar no meio da noite

Falta de uma boa noite de sono

Acordar cansado

Fadiga ou cansaço durante 0 dia

Diminuição do rendimento nas atividades do dia a dia

Diminuição da concentração nas atividades diárias

Frustração, agitação ou irritação

\section{Tristeza}

Sensação de vergonha

Dificuldade de sentir "cheiros" ou "gostos"

Nariz entupido

Iniciais de nome

e sobrenome:

Sexo: $\mathrm{MO} F \mathrm{~F}$
0 Nenhum problema

1 Problema muito leve

2 Problema leve

3 Problema moderado

4 Problema grave

5 Pior problema possivel

* Não há nenhuma resposta certa ou errada.

* Avalie como foram seus problemas nas duas últimas semanas.

* Caso tenha alguma dúvida no preenchimento do questionário, solicite auxílio.

\section{Resultado final:}

VERIFIQUE SUAPONTUACGÃO

Dez pontos ou mais:

Deve ser investigado

\section{Teste de Glatzel}
Obstrucão nasal?
Direita
Osquerda
Ambas
O Não apresenta

E-mail:

Data de

nascimento: 